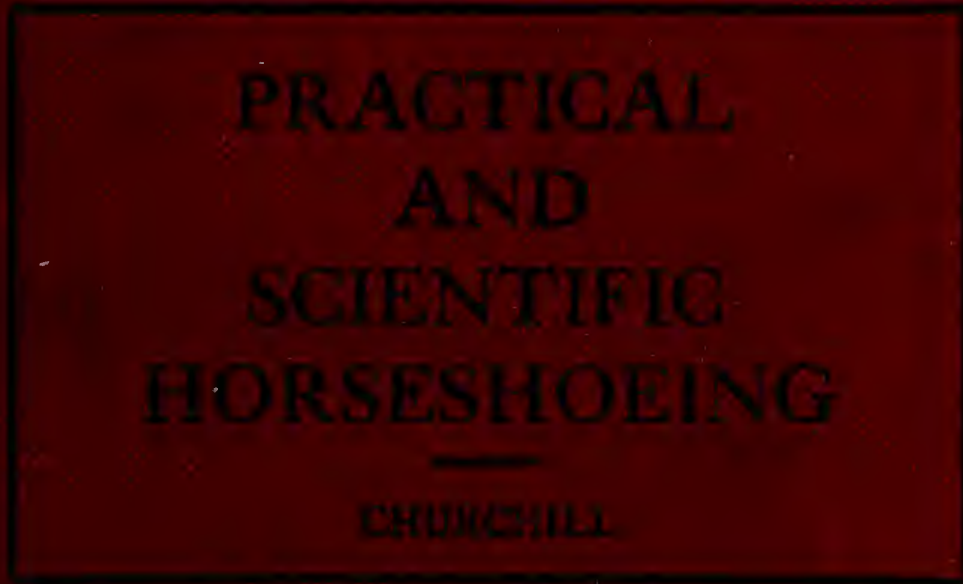

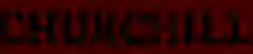

, 


$$
\text { 。 }
$$






\title{
Practical and Scientific
}

\section{Horseshoeing}

\author{
FRANK G. CHURCHILL \\ 11
}

1912.

FRANKLIN HUDSON PUBLISHING CO., KANSAS CITT, MO. 


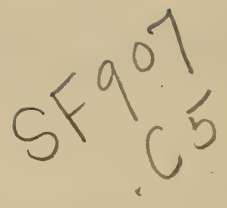

Copyright, 1912,'

By Frankliu Hudson Publishing Co.,

Kansas City, Mo.

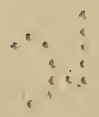




\section{PREFACE.}

While there is no scarcity of excellent books on horseshoeing, it is a fact that the great majority of horseshoers, and probably nine-tenths of our active horsemen, are not in possession of a text-book on this important science. This is probably due, at least in a measure, to the rather high price necessarily charged for such publications.

It has been the author's intention to compile a book which will fully cover the subject and at the same time permit those interested to obtain it at a very moderate cost.

The writer has spent many years of his life in the practical and theoretical work of horseshoeing, but it was not done with the idea of writing a Manual. Last year one of my student officers suggested that I publish my views on the subject, and, after much hesitation, the task was attempted.

An effort has been made to keep the text in sirıple language, and it is hoped that the reasons and explanations given will be clear and convincing to al! who may read it.

A great many publications have been consulted during the preparation of the text. However, I desire 
to especially acknowledge assistance received from "The Army Horseshoer" and "The Army Horse in Accident and Disease," both of which books have been conttinuously used during my connection with the Training School for Farriers and Horseshoers.

FrANK G. ChUtrChili.

Fort Riley, Kansas, March 24, I9I2. 


\section{CONTENTS.}

Chapter I.-Discussion on Shoeing............... 7

II.-Anatomy and Physiology of the Horse's Foot....................... 21

III.-Normal Shoeing . . . . . . . . . . . . 42

IV.-Shoeing for Gaits................. 64

V.-Diseases of the Feet. Pathological Shoeing 68

VI.- Miscellaneous Hints ............... 108

\section{ILLUSTRATIONS.}

Plate I. - The Bones of the Leg .............. 23

II. - The Foot .................... 30-31

III. - The Foot and Pastern Axis............. 43

IV.-The Prepared Foot. ................ 52

V.-Level of the Foot................. 55

VI.-Special Shoes for Correcting Faults in Gaits.. $\quad 75$

VII.-Pathological Shoes.................. 97 



\section{CHAPTER I.}

Principles OF Horseshoeing.

The fundamental principle of shoeing is to protect the foot from breaking and wearing away at a rate greater than the growth of horn supplied by Nature, and at the same time interfere as little as possible with the physiological functions of the different structure; of the foot.

That shoeing is a necessary evil has been admitted for centuries, and we find various means have been adopted for the protection of the feet-from the straw foot-pad used rather extensively in Japan to the modern American iron and steel shoes.

Eminent veterinarians, scientific horseshoers, and the most advanced horsemen have made long ani thorough study of the science of shoeing, with the result that to-day a remarkably perfect system of shoeing is being practiced throughout this country.

In the shoeing of our horses. we should always endeavor to keep the feet in a condition as close to that which Nature intended them as is consistent with the amount and class of work required of the animal, the state of weather existing, hardness of roads, etc.

Every nail driven into the wall of the hoof destroys a certain number of horn fibers and thus tends $t$ ) 
weaken the main weight-bearing part of the foot.

The shoe raises the frog from the ground and eliminates more or less the functions of the horny frog and elastic structures. This is much more noticeable with the calk shoe than with the plain or plate shoe. This is just one of the many points which should be understood and considered at the time of shoeing or reshoeing animals. How often is the shoer required to put a set of calle shoes on an animal when it is not only unnecessary, but decidedly objectionable. 'The horse-owner has perhaps had his animals "rough" shod all winter and fails to remember that the slippery condition of the roads ceased with the coming of summer. Here he has a chance to help Nature by getting the horse's foot down on the ground, but he continues the shoeing which does the feet the greatest harm. How many thousands of cases of lame and footsore animals could be avoided each year by an intelligent consideration of the shoeing of our horses.

Before going further into the discussion of scientific shoeing, I want to say a few words "direct" to the horse-owner, the master horseshoer, the journeyman, and the horseshoer's apprentice. But I don't want any of them to stop with the reading of this "direct appeal." I want each and every one of them to carefully read and study the remaining chapters in this manual. If this is done, I will feel that I am repaid 


\section{Practical and Scientific Horseshoeing}

for many years spent in the work and study of scientific horseshoeing. And I will also feel that the condition of many of our poor horses las been improved by the practice of some, if not all, of the principles laid down in this work.

To the Horse-Ozuner: It is considered most desirable that every horse-owner and trainer should thoroughly understand the theory of shoeing. It is hoped that the readers of this book may be placed in a position to know when their horses are in need of the shoer's care, and when the shoer has done his work properly.

The United States Government has at last realized the importance of proper shoeing, and every year some, twenty-five officers of the Mounted Service are sent to a school for a course of practical and theoretical horseshoeing. That the service is greatly benefited thereby is apparent to anyone who may have an opportunity to examine the the feet of the army horses.

The foot is the most complicated part of the horse and is most susceptible to injury and disease.

The old maxim, "No foot no horse," is true. Nature's work in the construction of the foot was marvelous. The horny frog, situated between the bars in the lower surface of the foot, acts as a buffer or cushion to break the jar and concussion when the foot strikes the ground, thus avoiding injury to the various 
parts contained within the foot. It also assists the circulation of the blood through the foot. And proper circulation of the blood is necessary if the foot is to be kept in a sound and healthy condition.

Shoeing in such a way as to keep the foot as near a state of Nature, and at the same time to protect it from too rapid wear on hard roads, should be the aim of every horse-owner. It is economy to take proper care of the feet. There is nothing saved by insisting on having heavy or calked shoes put on your horses simply to get more wear out of them. You may cut down the shoeing bill, but the veterinarian's account in caring for your horse's neglected and damaged feet will make it a mighty expensive practice. By allowing the feet to accumulate an excessive growth of horn, and by the continued use of the calk shoe, the horny frog and elastic structures cannot perform their proper functions. A diseased condition of the foot is the result.

Front feet, on account of the amount of concussion they receive, are more susceptible to injury than are the hind.

Contracted heels, corns, quarter and toe cracks, side bones, etc., are the diseases most common in case.s where the proper shoeing of the feet is not attended to. As a result of this neglect, the animal depreciates in value, and in many cases it is necessary to lay the 


\section{Practical and Scientific Horseshoeing}

horse up for treatment at considerable expense and much inconvenience.

This might be avoided by giving the feet more careful attention Though it may cost a trifle more for shoeing. it is money saved in the long run. A light shoe is better than a heavy one, for the reason that the heavier the shoe the more labor on the tendons and ligaments and the more readily the horse becomes fatigued. Fatigue induces stumbling and interference of the limbs.

The lightest shoe that will wear for a reasonable length of time is the best shoe to use.

The plain shoe is better than the calked, as it keeps the foot nearer a state of nature and allows the different parts to properly perform their functions.

This statement is often made: "My horse cannot stand up on city pavements without calks on account of its slipping." I have found by experience that under ordinary conditions a horse will stand up as well with the plain shoes as with calks. This applies particularly to the front feet. In case of heavy drafthorses, shoe plain in front and calks on the hind shoes. Most of the propelling is done with the hind feet.

A horse that is accustomed to wearing calks will be a little timid at first on pavements with the plain shoe, but will soon get used to them and travel easier and better than with the former. 
The shoes should be removed and the feet trimmed once a month. If the shoes are not worn, have them reset. Many horse-owners think that as long as the shoes stay on the feet the horse does not need shoeing.

The average growth of a healthy hoof is about three-eighths of an inch per month. 'The horn fibers of the wall grow downward and forward, in a straight line, at an angle of from 43 to 55 degrees. The hoof is bell-shaped; its lower horder, or bearing edge, being the greatest in circumference. The shoe is fitted to the outline of this border, except at the heels where it is fitted a trifle fuller to allow for the expansion of the quarters and heels. As the wall grows the circumference of the foot becomes greater, and in time it overgrows the shoe, causing corns, contracted feet, and other diseases. The foot is continually changing in shape, while the shoe is not.

The horse that is turned out to pasture or workerl barefooted should have its feet trimmed frequently (every three weeks), as the wear of the feet is nct always uniform. This unevenness of the hoof throw's the foot out of its natural position and in many cases causes injury to the foot and leg by an unequal distribution of weight on the horn structures and an overtaxing or straining of the tendons and ligaments.

The feet of the growing colt should be kept levcl and the edges of the wall rounded to prevent break- 
ing; thus we avoid deformity of the feet and enlargements of the limbs. By doing this the feet will also be in a condition for shoeing when the animal is sent to the shoer for its first shoeing. Again, the colt, by having its feet frequently handled when young, will not resist the shoer, as many young animals do. Many young animals are spoiled in the first shoeing. A horse should be trained for shoeing just the same as it is trained for driving or riding.

Most of the horses that are classed as refractory while being shod have been brought to this condition by improper handling when green and unaccustomed to the sights and sounds of a shoeing shop. It is as much the duty of the horse-owner and the horseshoer to gradually train a young horse to submit to shoeing; as it is to give him medicine when sick. Summary methods not only ruin the horse's disposition, but subject the shoer to constant danger of injury. The first step should be to teach the young animal that raising his feet will do him no harm. This should be taught by the horse-owner or a competent assistant before the horse ever enters a shoeing shop.

To raise the fore foot, stand with your back to the animal's head and place your inside hand on its shoulder; then bend over and run your hand gently down the back of the leg until the fingers, with the thumb on the outside, are just above the fetlock; your shoulder 
is pressed against the shoulder of the horse and forces the animal's weight upon the opposite fore foot. A slight grasp of the hand is usually sufficient to induce the horse to raise the foot.

To raise the hind foot, one should stand at the horse's flank with his back to the animal's head and his outside foot advanced; the hand nearest the horse is placed upon the animal's hip, gently pushing the weight upon the opposite leg; meanwhile the other hand is run slowly down the back tendons below the hock; the leg is grasped under the fetlock and is slight-. ly raised forward; now swing your inside leg under the horse's leg and extend it to the rear as in the position for shoeing. When the young horse surrenders his foot, lower it gently and pat him. After the horse gets accustomed to having his feet handled, begin to get him familiar with the hammer by tapping gently on his feet with the brush or currycomb.

The next step is to let the horse grow accustomerl to the shop. While the shoer is at work on a quiet horse, the young animal should be led into the shop, and held by the person who has been taking care of it and who has been raising its feet. The animal should not be tied. When the animal shows neither timidity nor excitement, the shoer may begin work on the feet. Frequently the removal of the surplus growth of horn is all that can be accomplished without excitement or 
resistance. At the first sign of either, work for that day should be abandoned and the horse removed from the shop. Patient, quiet work will eventually succeed, and thereafter each shoeing is more easily accomplished.

To the Master Horseshoer: In order to shoe horses intelligently, the shoer should have a thorougin knowledge of the anatomy and physiology of the foot. Many men engaged in shoeing, and wha believe themselves to be first-class workmen, are almost entirely at sea when mention is made of "the sensitive structures," "the elastic structures," etc. A thorough and systematic study of the contents of this book, if done by every shoer, would be of untold benefit to the shoers themselves, to the horse-owner, and to the horse.

Every shop should have several sets of the bones composing the horse's foot--the bones from the fetlock joint down. A vertical section of the foot and pastern (See Plate II.) should also be part of the shop's equipment. This can so easily be accomplished that the failure to do so would be sufficient excuse for any horse-owner reading this book to take his shoeing away from the shop not so equipped to a place whete the master workman has shown a desire to maintain or increase his knowledge, and also that of his workmen, in the theory and practice of horseshoeing.

These specimens may easily be obtained in any city 
or town in the country. Horses, like men, are dying or being killed every day. Ask the man who has just. lost a horse to give you a conple of legss, and tell him why you want them. He would respect the interest thus shown by you in your trade, and he will probably want to ask you a question or two. All this leads hin to your place of bisiness with his shoeing.

After obtaining the feet, they can be prepared on your own time. Take the neatest and most symmetrical foot and, after removing it from the upper limb at the fetlock joint, clip the hair close. Then put it in a vise with the bearing surface of the foot down. Select a sharp hand-saw (or a butcher's saw) and begin at the top of the os suffraginis and cut the foot into two equal parts, the cut being guided so as to pass directly through (not across) the cleft of the frog. After this has been done, clean the parts with a solution of bichloride of mercury and put them away in a box of salt for a couple of months. At the end of this time get your foot out, clean it up, and let it become thoroughly dried out. The bones of the foot can be boile $i$ out, cleaned, and allowed to dry. Your friend the veterinarian can give you advice and suggestions in preparing these specimens.

It is to your advantage, and also that of the horseowner, to talk over the shoeing of all animals coming into your shop. Get the owner interested in the shoe- 
ing of his animal by asking him how it travels, whether it strikes or stumbles, and numerous other questions occurring to you from time to time. Explain to him the necessity for bringing the animal to the shop regularly for reshoeing. The feet need attention, whether the shoes are badly worn or not.

Encourage your journeymen in the study of the anatomy and physiology of the foot. It will repay you tenfold. Your apprentice, the horseshoer of the future, should have his interest in the work frequently stimulated. See that he is started right in his study of the anatomy and physiology of the foot, in the shoeing for gaits, etc., as well as in his mechanical work. Then watch him "grow up."

A kind word of encouragement now and then is almost as good as an advance in pay. When one keeps his apprentice interested in his work it is soon found that he rapidly increases his value to the employer. If he does not show ability for this class of work, after a reasonable period of trial, inform him of the fact and advise him to try something else.

To improve the personnel of the calling, we must start at the bottom. Be particular in the selection of the timber for our shoers-to-be and exceedingly careful in their training. This would gradually eliminate the "cut-rater," as he is usually a man who is not a shining light in the profession. 
To the Journeyman: 'There is more to the art of shoeing than even the average mechanic realizes, while the average horse-owner simply realizes that the horse wears shoes, and that these shoes must occasionally be replaced. Shoeing, like a few other professions, is one in which perfection is most difficult to attain.

The horseshoer is either improving his work with practice and study or he is falling behind; there is no such thing as remaining stationary in this art. 'The energetic and ambitious men are advancing, and we know what becomes of the other kind-perhaps he is driving a team some place, working in a boiler factory, or has gone back to the farm. If a job is worth doing at all, it is worth doing well. The shoer cannot be too particular in performing his work, even to the most minute detail. Great care should be taken in the preparation of the feet. 'There is more science in leveling and balancing the foot than in the fitting and nailing on of the shoe.

In order to level a foot, the shoer must first be able to determine "when the foot is level." This is not an easy matter, and in cases of deformed feet it is a decidedly difficult piece of work. Upon reading this, please question yourself as to whether you can absosolutely level a foot. Read the chapter on "Normal Shoeing," and then examine your first job and determine the question. I believe that it is safe to say that 
fifty per cent of the animals shod are turned out with at least two feet which are not level.

To the Apprentice: To become a successful horseshoer, the apprentice should possess the following qualifications: first, a fondness for horses; second, patience and an even temperament; third, natural mechanical tendency; fourth, determination to overcome difficulties.

Cultivate patience in the handling of horses. Mucin more can be accomplished with kindness than by abusive treatment of animals.

The beginner is awkward in holding and working on the foot and the animal becomes tired and fretful. The animal endeavors to get away, but instead of losing your temper and blaming the horse, remember that the fault is with you. Speak quietly to the horse, and move around him slowly. Talking in a loud and boisterous manner, or approaching him with a rush, will only add to his excitement and make it more difficult for you to handle him.

Be observing of the work going on around you. Your education is obtained principally in this manner, the workmen having but little time to devote to your detailed instruction.

When given a piece of work to perform, take time to do it well, not slighting it in the smallest detail. 
Try to do each piece of work better than the preceding one.

Do not try to advance too rapidly, as this is generally to the detriment of performing good work.

Acquaint yourself with each part of the work thoroughly before attempting something new. Your future ability depends on the thoroughness with whic's you have learned in the beginning. Accuracy first, then acquire speed.

You cannot start too soon on the study of the anatomy and physiology of the horse's feet. Continue this with your practical work.

Do not make the mistake of leaving one employer for another before the expiration of your apprenticeship. Different methods prevail in different shops. and the apprentice is liable to become confused as to the correct way of shoeing.

Though progress is slow, and the pay not very large, it is worth your time and energy.

Make up your mind to become a first-class shoer, or find some other occupation. 


\section{CHAPTER II.}

\section{Anatomy.}

By anatomy of the foot and leg is meant a description of the various parts entering into its formation; and by physiology is meant the functions or uses of these parts.

For pathological shoeing and shoeing for gaits it is essential that the horseshoer should thoroughly understand the anatomy and physiology of the leg and foot, both front and hind. For normal shoeing all shoers must have unquestionable knowledge of the construction and workings of the feet from the fetlock to the ground, if the work is to be done in an intelligent manner. Study should begin with the framework of the leg;. the joints, ligaments, muscles and tendons, sensitive, elastic and horny structures, the circulatory and nervous systems, and the expansion and contraction of the foot, etc., being taken up in their natural sequence.

Bones of the Legs: Named in the order from above downward, the bones of the fore leg are the scapula. humerus, radius, ulna, carpus, large metacarpal and two small metacarpals. Two small sesamoids form part of the fetlock joint and we will consider them as belonging to the upper leg. In the hind leg, naming them in the same manner (from above downwards) as was 
done for the fore leg, we have the femur, the patella, tibia and accessory leg bone called the fibula, the tarsus (six bones of the hock), consisting of the astragalus, calcaneum, cuboid, cuneiform medium, magnum and parvum, large metatarsal, two small metatarsal bones, and the two sesamoids.

\section{Joints.}

A joint is that part or space included between two articulations. Over the adjacent surfaces in the joint is a thin and very smooth layer of articular cartilage. A lubricating fluid, synovia, joint oil, is required to reduce the amount of friction; this fluid is formed by the synovial membrane and the latter is confined and protected by the capsular ligament which completely surrounds the joint. Outside of the capsular ligament are binding ligaments holding the bones in position.

Joints of the fore leg are: shoulder joint, formed by the lower end of the scapula and the head of the humerus; elbow joint, by the radius, ulna, and humerus; knee joint, by the radius, seven small bones (carpals), and the upper end of the metacarpals; fetlock joint, by the large cannon, upper pastern bone, and the two sesamoids; pastern joint, by the upper and lower pastern bones; coffin joint, by the lower pastern, coffin bone, and shuttle bone.

Joints of the hind leg: hip joint, formed by the 
Fig. I .

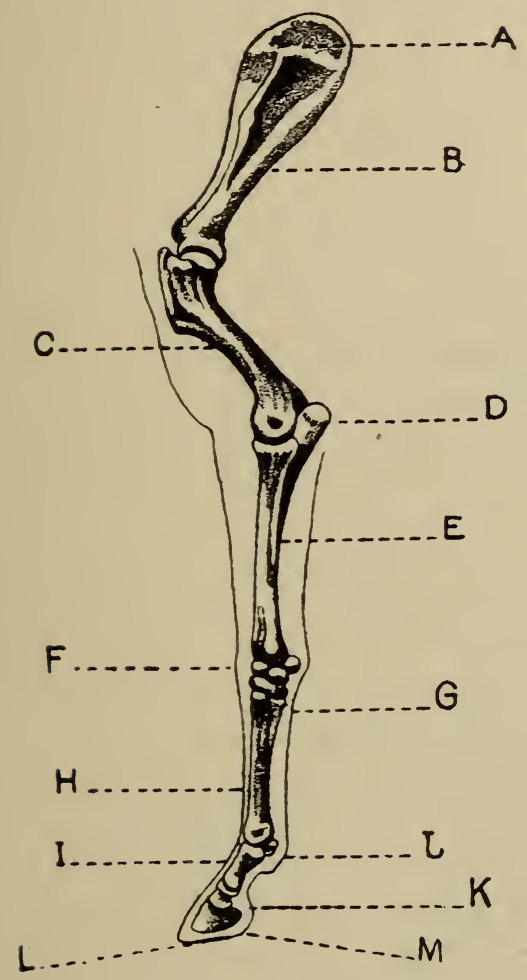

Fig. 2.

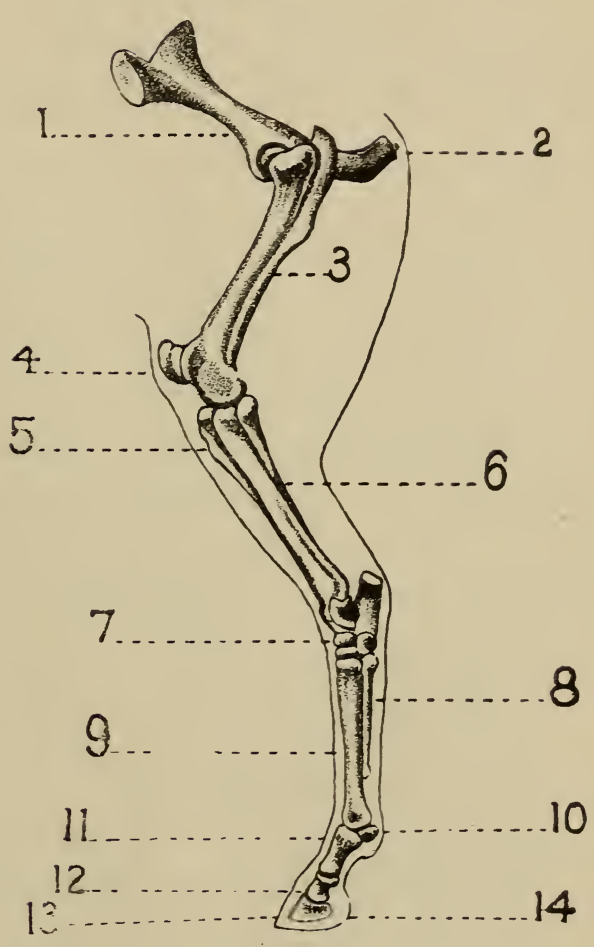

Plate I.

\section{FORE LEG:}

A. cartilage of prolongation: $\mathrm{B}$, scapula: C, humerus: D, ulna: $E$, radius; $F$, carpus: $G$. small metacarpal: $H$, large metacarpal: I, os suffraginis: J, sesamoid: $K$, os coronæ; L, os pedis: $M$, os navicularis.

\section{HIND LEG:}

I, pelvis; 2, ischium: 3 , femur: 4. patella: 5 , tibia; 6 . fibula: 7 . tarsus; 8 , small metatarsal; 9 . large metatarsal; 10 , sesamoid: I 1, os suffraginis: I 2, os coronæ: 13. Os pedis; 14, os navicularis. 
socket of the pelvis and the head of the femur; stifle joint, by the lower end of the femur, head of the tibia, and the patella; hock joint, by the lower end of the tibia, six small bones (tarsals), and the upper ends of the metatarsals.:

\section{Ligaments.}

Ligaments are, generally speaking, strong bands of white fibrous inelastic tissue. Their principal use is ta firmly bind joints together, thus preventing vibration and diminishing friction.

The suspensory ligament is a long, strong band of fibrous tissue originating in the back part of the lower bones of the knee and in the uppery part of the large metacarpal bone; it occupies the space between the small metacarpal bones and passes down immediately behind the large metacarpal bone, lying between it and the tendon of the flexor pedis perforans; it bifurcates opposite the lower third of the large metacarpal bone and becomes attached to the sesamoids, whence the parts pass forward and downward, joining the tendon of the extensor pedis just above the pastern joint. Ii is thin and comparatively weak near the knee, but as it nears the fetlock joint, it almost equals the back tendons in substance, and its size and wiriness to the touch may be taken as an indication of the power of any particular leg to resist a breakdown. 
However, this ligament is liable to numerous accidents and it is often found to be badly sprained.

The suspensory ligament of the hind leg corresponds in every particular to that of the fore leg.

The calcaneo-cuboid ligament stretches from the posterior border of the calcaneum to the posterior part of the cuboid, ending on the head of the external splint bone. A sprain of this ligament is known as a "curb."

Capsular ligaments, as we have seen, are pouchshaped, are found around joints, and are intended to protect the lubricating apparatus inside.

\section{Muscles and Tendons.}

The muscles of the limbs are known as voluntary muscles and they are under the direct control of the will. They are also classed as long muscles.

A tendon is a tough cord or band of dense, inelastic, white fibrous connective tissue, uniting a muscle with some other part and transmitting the force which the muscle exerts.

Extensors are those that have the power of straightening the limb; flexors, of bending the limb.

The extensor pedis tendon is the principal extensor of the fore leg; it originates at the lower extremity of the humerus, and its fleshy portion continues to the lower third of the radius; at this point it becomes tendinous, and, passing down over the knee, continues 
along the front of the leg and becomes attached to the upper and front part of the os pedis.

The flexor pedis perforatus originates from the inner and lower part of the humerus; it passes down the back part of the leg, becoming tendinous just above the carpus; behind the pastern it bifurcates, forming a ring for the passage of the tendon of the perforans, and becomes attached to the sides of the os coronæ. Its action is to bend or flex the knee, fetlock, and pastern.

The fle.ror pedis perforans originates with the perforatus; its fleshy portion passes down and is attached to the back part of the radius; its tendinous portion, beginnling at the knee, passes down the leg between the large metacarpal bone and the tendon of the perforatus, over the back of the fetlock, through the arch formed by the division of the tendon of the perforatus, and i.: attached to the under surface of the os pedis. Its action is to flex the knee and all joints below.

The extensor pedis of the hind leg originates from the lower and front part of the femur; its fleshy portion extends downward along the front surface of the tibia to the hock, where it becomes tendinous; passing thence down the front of the leg, it is attached in the same manner as the extensor pedis of the front leg. Its action is to extend the leg and flex the hock.

The flexor pedis perforatus of the hind leg origi- 


\section{Practical and Scientific Horseshoeing}

nates at the back and lower part of the femur. Its fleshy portion extends about half-way down the tibia, then becomes tedinous, and passes over the point of the hock, continues down the back of the leg, and is attached in the same manner as the perforatus of the front leg. Its action is to extend the hock and to flex the fetlock and pastern.

The flexor pedis perforans of the hind leg originates at the upper and back portion of the tibia. Above the hock it becomes tendinous and passing down over the inner and back side of the hock is attached to the os pedis in the same manner as the perforans of the front limb. Its action is to extend the hock and to flex the joints below.

\section{The Foot.}

We have considered that "the foot" includes a!l that part of the limb from the fetlock joint to the ground.

For the study and consideration of the foot, we will divide it into the following parts:

I. The bones and certain elastic structures of cartilage and fat.

2. The highly sensitive flesh, which covers the framework.

3. The box or case of horn, called the hoof, which incloses and protects the internal structures. 


$$
\text { Bones of the Foot. }
$$

The bones of the foot form a column extending downward from the fetlock into the hoof, and are named as follows: os suffraginis (long pastern bone), os coronae ('short pastern bone), os pedis (coffin bone), and os naricularis (shuttle bone).

The os suffraginis is about one-third as long as the metacarpal bolne and reaches from the fetlock joint above to the pastern joint below; its upper end shows a shallow cavity on each side, separated in the middle by a deep groove, and into this surface fits the lower end of the metacarpal bone. The lower end is much smaller and narrower than the upper; on each side is a small convex surface, the two surfaces being separated in the middle by a shallow groove. This extremity meets the upper end of the os coronæ and forms the pastern joint.

The os coronae follows the direction of the os suffraginis downward and forward and lies between the pastern and coffin joints, its lower end being within the hoof.

Its superior surface shows a shallow cavity on each side, with a ridge between them to fit the lower end of the os suffraginis. The lower surface of this bone shows a convex part on each side, separated by a 
groove, to fit the upper surface of the coffin bone in the coffin joint.

The os pedis is an irregular bone, situated entirely within the hoof, and is similar to it in shape.

The front surface is known as the wall surface; it shows a number of small openings, called foramina, for the passage of blood-vessels and nerves, and is roughened to give attachment to the soft sensitive laminæ covering it. At the top of this surface, in front. is a ridge called the pyramidal process, to which is attached the extensor pedis tendon.

The upper surface helps to form the coffin joint and is called the articular surface; it shows two cavi.. ties, separated by a ridge.

The lower surface is half-moon-shaped, concave and smooth, and is covered by a sensitive sole. This surface is sometimes spoken of as the "sole surface."

Just back of the articular surface is a small triangular surface to fit the os navicularis bone.

Just back of the sole is a rough surface, to which is attached the flexor pedis perforans tendon; it is called the tendinous surface.

On each side of this surface is a groove running forward and terminating in an opening, called the plantar foramen; an artery and a nerve enter the bone and a vein leaves it throngh this opening.

On each side of the os pedis, extending backward, 
is a prolongation, called the roing. Each wing is divided by a notch and then by a groove, which runs forward on the outside of the bone; an artery lies in this notch and groove.

The os navicularis is an irregular bone situated behind and below the os coronæ and behind the os pedis, articulating with both bones. Its long axis is perpendicular to the axis of the foot. The extremities of the bone are attached to the wings of the os pedis; the lower surface is covered with cartilage, which forms a smooth surface for the movements of the tendon of the flexor pedis perforans muscle.

\section{Elastic Structures of the Foot.}

All of the parts of the foot, except the bones, are more or less elastic or "springy"; but certain parts have a verty high degree of elasticity, their special use being to overcome the effects of concussion or jar when the foot strikes the ground and to prevent injury. These parts are referred to as the elastic structures of the foot. They are the lateral cartilages and plantar cushion, or fatty frog, as it is sometimes called.

The lateral cartilages are thin plates of cartilage, one attached to the top of each wing of the os pedis, and extending backward and upward so far that their upper borders may be felt under the skin above the coronet at the heels. 
The plantar cushion is a very elastic wedge-shaped pad, which fills up the space between the two lateral cartilages on the sides, the sensitive frog below, and the flexor pedis perforans tendon above.

The point or anterior part of the plantar cushion extends forward to the ridge which separates the sole from the tendinous surface of the os pedis. The base is covered by the skin above the heels.

\section{Sensitive Structures of the Foot.}

Over the bones and elastic structures of the foot is found a complete covering of very sensitive flesh, and from each part of this covering some part of the hoof is secreted or formed. The divisions of this layer of flesh are called the sensitive structures of the foot. They are the coronary band, sensitive laminae, sensi. tive sole, sensitive frog, and the perioplic ring. This ring is sometimes called the "coronary frog band."

The coronary band is a thick convex band of tougin flesh, about four-fifths of an inch wide, and exten's entirely around the top of the hoof from one bulb of the heel to the other; in front it is attached to the extensor pedis tendon, and on the sides to ligaments of the coffin joint, to the lower end of the os coronæ, and to the lateral cartilages. The surface of the coronary band is covered with small pointed projections or villi. 
The coronary band secretes or forms the principal part (middle layer) of the wall of the hoof.

The sensitive laminae (sometimes called fleshy leaves) cover and are firmly attached to the wall surface of the os pedis and to the lower part of the outer surface of the lateral cartilages. These delicate leaves of the flesh dovetail into the horny laminæ which they secrete, and with them serve to fasten the wall of the hoof to the os pedis and to the lateral cartilages.

The sensitive sole covers the sole surface of the os pedis, is covered with villi, and secretes the horny sole.

The sensitive frog covers the lower surface of the plantar cushion, and from its villi the horny frog is grown.

The perioplic ring is a narrow band of flesh running around just above the coronary band and separated from it by a faint groove. From the fine villi on the surface of this ring the delicate fibers grow which form the periople.

\section{The Hoof.}

The box or case of horn, called the hoof, which incloses and protects the other structures of the foot, is divided into three parts-wall, sole, and frog. In a healthy foot these parts are solidly united.

The wall is the part seen when the foot is on the ground; it extends from the edge of the hair to the 


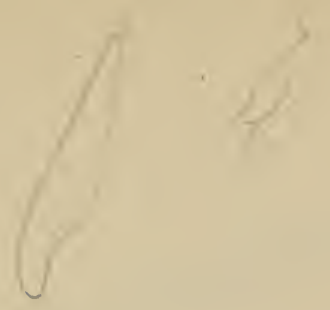




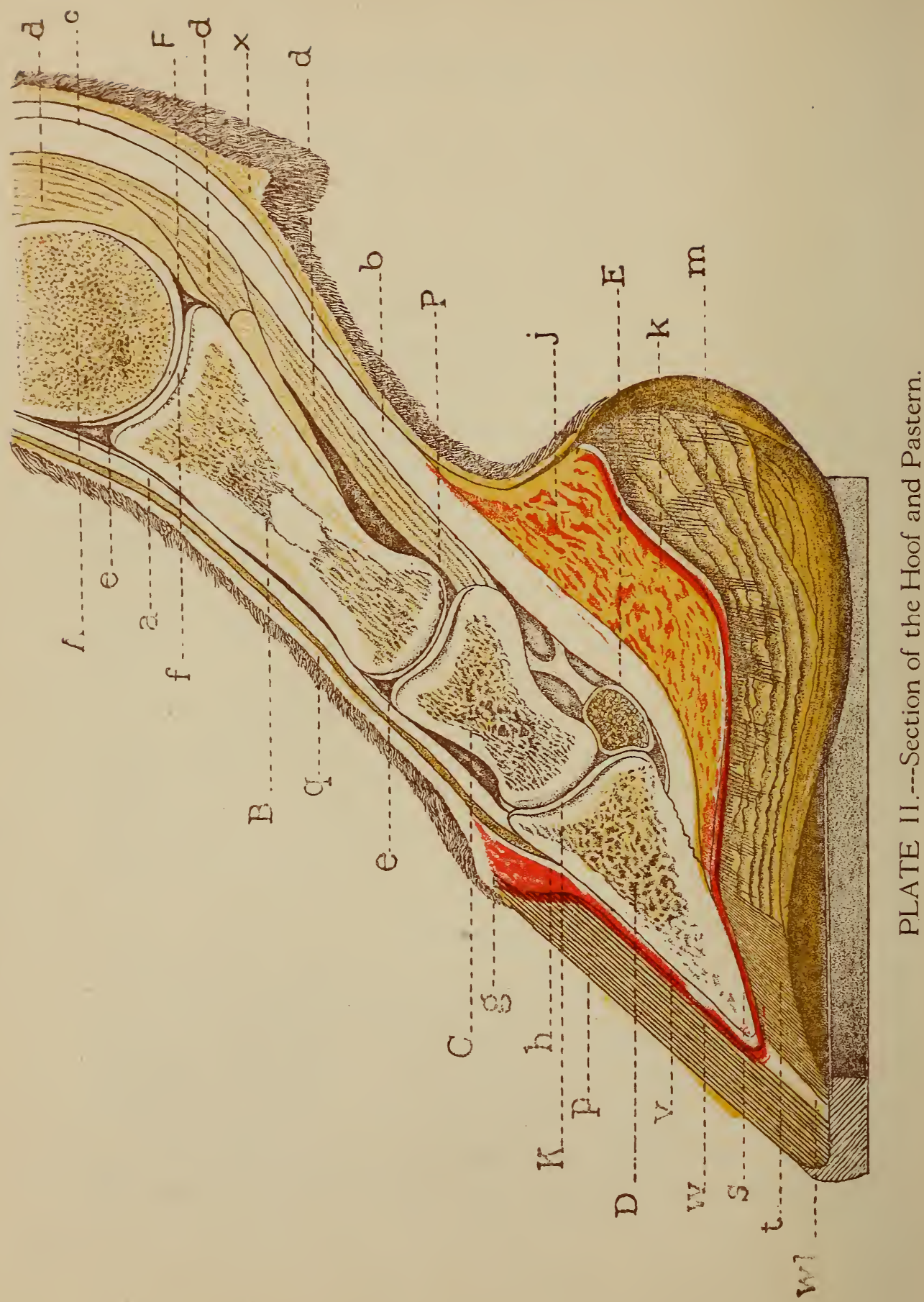




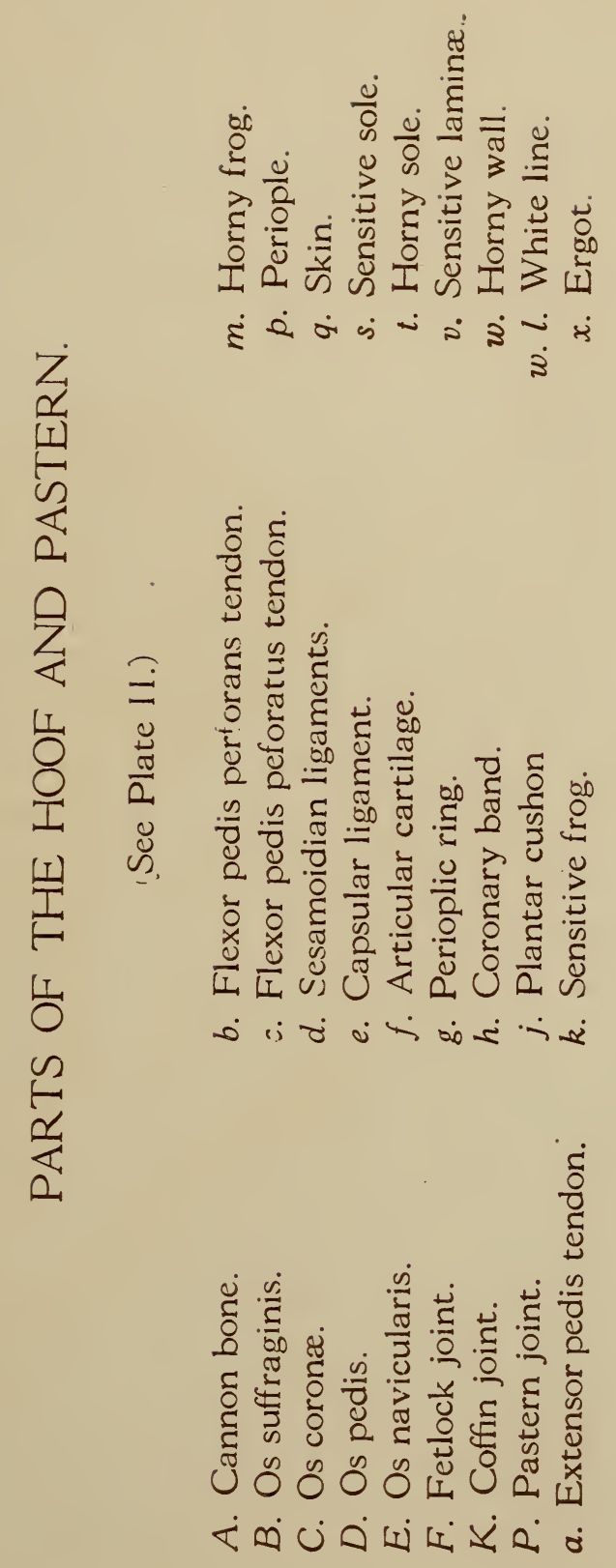



ground and is divided into the toe, quarters, heels, and bars; it has an internal surface, an external surface, and an upper and a lower border.

The toe is the front part of the wall in front of the first nail hole on either side. It is steeper in the hind foot than in the fore. The quarters extend backward from the toe to the point where the bar leaves the wall in an inward and forward direction. The hee! or buttress is that part of the wall back of the point where the bar leaves it, and the bar is the division of the wall running from the heel to within about one inch of the point or apex of the frog. It lies between the horny sole and the frog. (See Plate IV.)

The external surface of the wall is covered by a thin varnish-like coat of fine horn, called the periople.

The internal surface of the wall is covered by from 500 to 600 thin plates or leaves of horn, called the horny laminae. Between the horny laminæ, which run parallel to each other and in a direction downward and forward, there are fissures into which dovetail the sensitive laminæ, and this union binds the wall of the hoof to the os pedis and lateral cartilages.

The upper border of the wall shows a deep groove (coronary groove) into which fits the coronary band.

The lower border is called the "bearing edge" (or "spread" in the unshod foot) and is the part to which the shoe is fitted. 
The horny sole is a thick plate of horn, somewhat half-moon-shaped, and has two surfaces and two borders.

The upper surface is convex (bulging upward) and is in union with the sensitive sole from which the horny sole grows. The lower surface is concave and is covered with scale or crusts of dead horn, which gradually loosen and fall off.

The outer border of the sole joins the inner part of the lower border of the wall by means of a ring of soft horn, called the white line. This mark or line is sometimes called the guide line, as it shows where the nail should be started in shoeing.

The inner border is a V-shaped notch and is in union with the bars, except at its narrow part where it joins the frog.

The horny sole protects the sensitive sole and should not, in a healthy foot, bear weight, except a very narrow border at the white line, an eighth or tenth of an inch in width.

The horny frog is the wedge-shaped mass of horn filling up the triangular space between the bars. The lower surface shows two prominent ridges, separated behind by a cavity, called the cleft, and joining in front at the apex or point of the frog; these ridges terminate behind in the bulbs of the frog. Between the sides of the frog and the bars are two cavities, called the 
commissures. The upper surface of the horny frog is the exact reverse of the lower and shows in the middle a ridge of horn, called the frog stay, which assists in forming a firm union between the horny and sensitive frog. The horny frog serves to break the jar or concussion by acting as a cushion or pad; it also protects the sensitive frog and prevents the foot from slipping.

Structure of Horn.

The horn of the hoof presents a fibrous appearance and consists of very fine horn fibers or tubes, similar to hairs, running downward and forward and held together by a cementing substance. The horn fibers of wall, sole, and frog all run in the same direction, downward and forward, the only difference being that those of the frog are much finer and softer and run in wavy lines, whereas the fibers of wall and sole are straight.

The horn fibers grow from the small villi, which cover the surfaces of the coronary band, sensitive sole, and sensitive frog.

Circulation of Blood Through the Foot.

The large metacarpal of the fore leg and the great metatarsal of the hind leg each divides just above the fetlock into two branches. These branches are called 
the external and internal digital arteries, one on the inner and one on the outer side of the fetlock joint. They follow the borders of the flexor tendons downward and terminate inside of the wings of the os pedis. Each of the internal and external digital arteries gives off five branches-the perpendicular, transverse, artery of the frog, preplintar ungual, and plantar ungual.

The perpendicular artery is given off at right angles about the middle of the os suffraginis, defscends on the side of the pastern, bends forward and joins with the artery of the same name from the opposite side and forms the superficial coronary arch. From this arch branches descend to the coronary band.

The transwerse artery comes off under the upper border of the lateral cartilage, runs forward, and joins its fellow from the opposite side between the extensor pedis tendon and the os coronx. The deep coronary arch is the name given to this arrangement of the arteries, and branches from this arch also supply the coronary band.

The artery of the frog rises behind the pastern joint at the upper border of the lateral cartilage. It has two branches-a posterior, which runs back and supplies the bulb of the heel, and an anterior, which runs forward and downward through the plantar cushion and supplies the sensitive frog.

The preplantar ungual artery is given off inside the 
wing of the os pedis, passes through the preplantar notch, and runs forward along the preplantar groove on the side of the bone. It helps supply the sensitive laminæ with blood and sends some small branches into the bone to join branches from other arteries.

The plantar ungual artery is the terminal or last branch of the digital artery (is a continuation of that artery) and enters the os pedis at the plantar foramen.

The two plantar ungual arteries run forward within the bone and unite to form the circulus arteriosus. From this circle spring ascending and descending branches, which supply the sensitive laminæ and sensitive sole. The ascending branches, called the anterior laminal arteries, leave the bone through the small openings (foramina) and supply the sensitive laminæ in front. The descending branches, called the inferior communicating arteries, are about fourteen in number and emerge from the bone by the openings just above its lower edge; they unite to form a large trunk, running around the toe of the os pedis, called the circumfle. $x$ artery, and this artery gives off ascending and descending branches. The ascending branches pass into the sensitive laminæ, and the descending branches, called the solar arteries, numbering about fourteen, run backward through the sensitive sole to form a second circle, called the inferior circumflex artery,

The veins of the foot are arranged in networks, 
each network or plexus named from the part in which it is located. The solar plexus is found running all through the sensitive sole. The laminal plexus runs through and under the sensitive laminæ. The coronary plexus surrounds the os coronæ and upper part of the os pedis, just under the coronary band.

The veins of the frog are those found in the plantar cushion and sensitive frog; the interosseous veins form a network within the os pedis. The veins of the foot all unite above to form a large trunk, called the digital vein, which runs along the digital antery and carries the blood back toward the heart. The veins of the foot are valveless below the middle of the pastern, an arrangement which allows the blood to flow in either direction when pressure is applied, and thus prevents injury.

\section{Nerves of the Foot.}

The nerves of the foot supply feeling or the sense of touch to the parts. The large nerve cord on either side of the limb divides at the fetlock joint into three branches, called the digital nerves-the anterior, the posterior, and the middle.

The anterior digital nerve passes downward and forward and supplies the anterior or front part of the foot:

The posterior digital nerve, the largest of the three, 
passes down behind the digital artery to supply the structures in the posterior part of the foot. It gives off a branch which passes through the notch in the wing of the os pedis (in company with the preplantar ungual artery) to supply some of the sensitive laminæ; it also sends branches into the os pedis with the plantar ungual artery.

The middle branch is very small, is said to always join the anterior branch, and supplies the sensitive soie and fetlock pad.

The functions of most of the parts of the foot have been mentioned in passing, but there are some points in connection with the physiology of the font which need to be explained more in detail.

\section{Expansion and Contraction.}

When weight comes upon the leg, the os pedis descends slightly and causes the sole to descend and flatten. The plantar cushion and horny frog are compressed between the ground below and the structures above; this compression causes them to spread out sidewise, carrying outward the lateral cartilages and bars and the wall at the quarters. This is called expansion. When welight is removed from the leg, the pantar cushion becomes thicker and narrower, and the lateral cartilages and quarters move inward to where they were before expanding. This is called contrac- 
tion. The elastic lateral cartilage is merely a flexible extension of the wing of the os pedis and would appear to have been specially designed for expansion and contraction at the quarters. It is also to be noted that the bars are a provision for this same purpose, since expansion and contraction could not take place if the wall formed a solid unbroken ring around the hoof. Without frog pressure, proper expansion is impossible.

In addition to breaking the jar when the foot comes to the ground, the plantar cushion has another important use. It assists in the circulation of the blood through the veins of the foot. When weight is placed upon the foot, the pressure on the plantar cushion forces the blood upward through the veins; then, when the foot is lifted and the pressure is removed from the horny frog and plantar cushion, the veins of the frog again fill with blood, and this pumping action is repeated with each step. Proof of this statement is seen when a digital vein is cut, by accident or in experiment. If the horse is walked, a jet of blood spurts out each time hel puts the foolt to the ground; but if he is allowed to stand, the blood flow's in a steady stream from the vein. Much injury to the foot often results from starting the horse off suddenly at a fast gait on a hard road after he has been standing for some time or when he first comes out of the stable. The circulation and the structures of the foot should have time to gradual- 
ly adapt themselves to the change from rest to severe work.

\section{Moisture.}

The wall of the healthy hoof is, by weight, about one-fourth water, the sole more than one-third, and the frog almost one-half. This water is supplied by the blood and preserves the horn in a tough and elastic condition. The hoof, particularly the frog, is capable of absorbing moisture from the ground. The periople, which covers the wall, prevents the evaporation of water, and therefore should never be rasped. As there is no similar covering for the sole and the frog, the layers of horn on their exposed surfaces dry out and die. The dead layers are hard and brittle, and gradually fall or flake off. As they preserve the moisture in the layers of live horn beneath, they should not be removed in preparing the hoof for shoeing. 


\section{CHAPTER III.}

\section{Normal, Shoeing.}

By normal shoeing is meant the shoeing of a sound foot of a horse with proper gaits.

\section{Preliminary Examinations.}

Three careful examinations should be made before old shoes are removed from the horse:

I. Of the shape and position of the feet at rest.

2. Of the evidence of wear in the old shoe.

3. Of the action of the feet when the horse is in motion.

For the first examination, the horse should stand at ease on the floor; the shape of each foot and leg should be observed from the front, from each side, and from the rear, care being exercised that the leg, at the time, is bearing its proper share of the animal's weight.'

The shoer first studies the natural pastern conformation. Is the pastern slanting inward, "toe in"? is it vertical, "straight"? or is it sloping outward, "toe out"? (See Plate III., Figs. I, 2, and 3.)

Having decided this point, he then studies the position of the "pastern axis" and the "foot axis." 


\section{PASTERN CONFORMATION.}

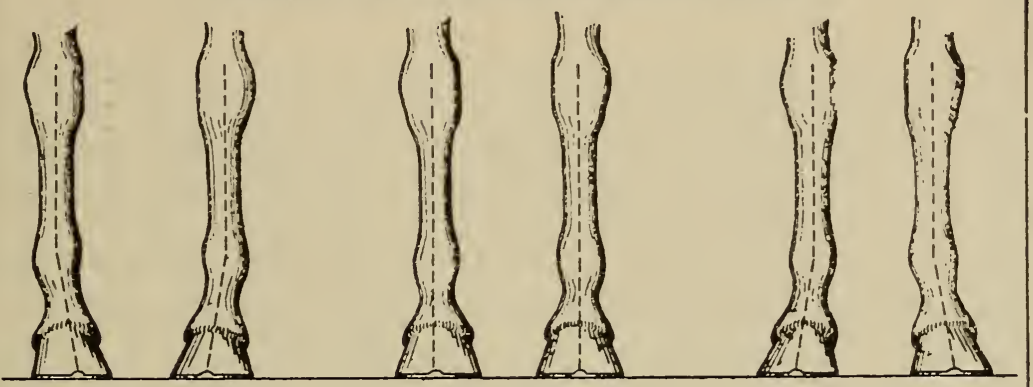

1. TOE IN

2. STRAIGHT

3. TOE OUT

\section{PREPARATION OF THE HOOF.}

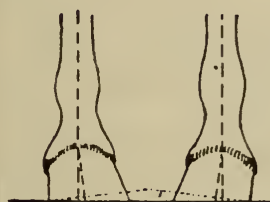

4. BROKEN OUT

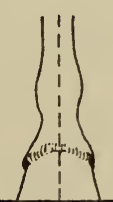

5. CORRECT

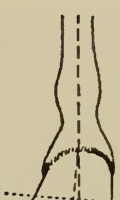

6. BROKEN IN

\section{PASTERN CONFORMATION.}

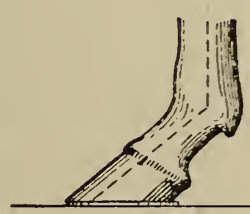

7. SLOPING

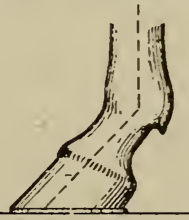

8. REGULAR

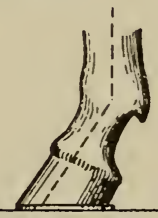

9. STUMPY

\section{PREPARATION OF THE HOOF.}

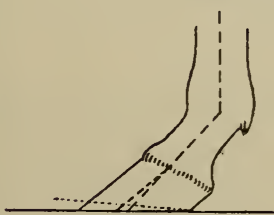

10. BROKEN BACK

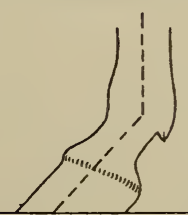

11. CORRECT

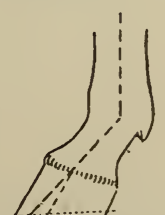

12. BROKEN FORWARD

PLATE III.---The Foot Axis and the Pastern Axis. 
As seen from the front, we may consider that the "pastern axis" is the imaginary line exactly splitting the pastern in two, and that the "foot axis" is the line exactly splitting the foot in two--that is, the line from the center of the toe to the center of the coronet.

These two axes should be in prolongation or appear to be one straight line, no matter what the natural pastern conformation (see Figs. I, 2, 3, and 5), and if the shoer finds this condition satisfactory, he will simply need to prepare the foot evenly for shoeing. But if the two axes do not appear as one straight line, there will be a break at the coronet. This is an indication that the foot was not level when last shod, and the horse is not standing correctly. If the line is "broken out" (Fig. 4), the prolongation of the pastern axis falls to the outside of the foot axis and the inner wall is too high; the fault is remedied by removing more of the inside wall than of the outside. If the line is "broken in" (Fig. 6), the prolongation of the pastern axis falls to the inside of the foot axis and the outside wall is too high; it should be taken down more than the inside. The dotted lines in the figures show the amount to be trimmed off.

It will be noticed that the "broken out" foot looks like the "toe in," and the "broken in" foot looks like the "toe out," but in the natural conformations there is no break at the coronet. 
Standing at the side, the shoer should notice the height of the foot, the length of the toe, and the slope of the line of the toe-that is, the front line of the hoof as seen from the side.

Here, again, we have three cases of natural pastern conformation: The "sloping," the "regular" and the "stumpy," Figs. 7, 8, and 9; but the linel of the toe should, nevertheless, be parallel in each case to the pastern axis as seen from the side.

By careful sighting from the side, draw a chalik line between the second and third clinches, with exactly the same slope as the line of the toe. This mark will generally have the same direction as the horn fibers. Now stand back and determine if this mark and the "pastern axis," as seen from the side, are one and the same line. If so, trim off the surplus growth evenly. If not, the line will be broken at the coronet. In "broken back," Fig. Io, the prolongation of the pastern axis (as seen from the side) falls to the rear of the foot axis and the toe is too high. It should be taken down more than the heel. In "broken forward" the prolongation of the pastern axis falls in front of the foot axis and the heels are too high. They should be taken down more than the toe.

The "broken back" looks like the sloping pastern and the "broken forward" looks like the stumpy pas- 
tern. The break at the coronet, however, is the sure guide.

For the second examination, the foot must be raised.

The wear of the old shoe should be carefully noted as a check on the preceding examination. If the shoe has worn evenly, its position on the foot was undoubtedly correct. If one side of the shoe shows more wear, (a) that side may have been fitted too closely, (b) there may be some fault in gait, (c) the foot may not have been properly levelled in the last shoeing, (d) the quarters, as frequently happens, may have grown unevenly since the last shoeing. Horses with long, sloping pasterns wear the shoe more at the heel, while those with short, upright pasterns wear the shoc more at the toe. There is a slight scuff at the moment of breaking over which produces a normal wear at the toe, but overworked horses and those suffering from disease often show more than this normal wear.

For the third examination, the horse, having free use of his head, should be led at a walk and at a slow trot upon level ground. Uneven ground will produce modifications of the natural gait, and a tight rein or a short hold on the halter shank will also alter the free, natural motion. The shoer assumes a squatting position and observes the feet as the horse is led past him, away from him, and towards him. The manner in 


\section{Practical and Scientific Horseshoeing}

which a foot leaves the ground, its path in the air, and the manner in which it is planted should be closely watched, in order to detect any of the defects of gait which can be remedied by intelligent shoeing.

In cases where it is known that the animal to be shod has normal gaits, and the second examination has not indicated an abnormal breaking over of the feet, only the first two examinations need be made. In all doubtful cases the third exam:nation should he made.

Upon completion of a case of shoeing to correct some fault in gait (required hy the third examination), the animal should be taken out and examined again at a walk and trot.

\section{To Prepare the Foot.}

With the horse standing evenly on its feet, examine the foot and pastern axes to determine the necessary changes, if any, to be made, besides the removal of the surplus growth of horn.

In preparing to raise a horse's foot, never approach the animal suddenly, for he will only be startled. A sudden pull at his foot or leg will probably disturb his balance, and the raising of the foot will be more difficult for both man and horse. The position for holding the foot for shoeing should be such that no unnecessary strain is placed upon the horse; such as holding 
the foot and leg too far to the side, too far to the rear, or by holding them too high. Such positions makc even the most quiet hor ses nervous and irritable; they cannot endure the pain of the strain on their muscles and tendons, and will jump and pull the leg away from the shoer in an endeavor to get in a more comfortable position. The shoer usually lays the blame upon the horse, considering him fractious and difficult to shoe. The fault is with the shoer, and the manner of handling the foot and legs, instead of the disposition of the horse. Loud or boisterous talking when working around horses is poor policy and should be avoider. as you excite the animal and make the work of shoeing doubly hard for yourself. Some horses, and particularly those of good breeding, are of nervous temperament and unless handled with care are easily spoiled for shoeing. If you lose your temper in hanciling a horse, walk away from him immediately and remain away until you have regained control of yourself. The horse is aware of your condition, even before you are, and will struggle to get away for fear of getting hurt. Much more can be accomplished by kind treatment than by abuse.

Then take the knife and pare away the dead horn near the white line until live horn is reached, being careful not to go farther back than the last nail hole. This is done to ascertain the amount of horn that may 
be removed and to facilitate the use of the nippers. The knife should never be used on the bars or the frog. The bars strengthen the hoof and assist in its expansion. Cutting therefore weakens them and prevents them from performing their function. Never use a knife on the hoof of a horse that has been running barefoot. The greatest care must be exercised in using the knife on flat feet, either natural or diseased.

The foot is then leveled, the shoer using the nippers and rasp.

The use of the nippers in preparing the foot for the shoe lessens the amount of rasping and does away with the use of the buttress. The nippers are superior to the buttress for this part of the work, being much easier and safer to operate. In preparing the foot for the shoe, the shoer has several important guides to assist him in this most particular operation:

First.-The live horn at or near the white line.

Second.-When the shoer can make the least impression with the thumbs, on the sole near the white line, the foot is down as much as it can be taken with safety. For this examination, take the foot in both hands and press with the thumbs near the white line; if the sole yields ever so slightly, no more horn should be rasped away or lameness is liable to result.

Third.-The size of the feet compared with the size and weight of the animal. There is a great difference 
in the thickness of the horny sole, between cup-shaped and flat feet. The cup-shaped foot, as a rule, grows faster than the flat foot, and the layers of horn as they dry out do not fall off; the sole being arched has a tendency to keep them from flaking off. With the flat foot the horny sole is less arched and the dead horn as it dries out readily flakes off. The horny sole of the flat foot is also naturally thinner than that of the cupshaped foot. Great care should be exercised in preparing the flat foot, for reasons given above.

With some horses having flat feet, and the size br:ing out of proportion to the size of the horse (or too) large), the feet are liable to make the animal clumsy in his gait. In cases of this kind, the feet should be taken down as much as conditions will permit, or until pressure is felt. With the cup-shaped foot sometimes the foot is too small in comparison with the size of the horse and should not be taken down until pressure is reached, as by so doing the foot is made too small to give proper support to the weight of the horse; the ground surface is not sufficiently large enough to steady the gait.

The rasp will remove a sufficient amount of the dead horn on the sole and bars while leveling the bearing surface of the foot for the shoe. A certain amount of dead horn on the sole is essential to keep the live horn moist and flexible, also to protect the sensitive 
sole from bruising. If the knife is used on the sole and bars, the shoer is apt to remove too much horn the bars are weakened and the live horn of the sole is exposed, allowing the moisture to evaporate. The same is applicable to the horny frog. It should not be trimmed, with the exception of the removal of loose particles, but should be left to attain its full size. Excessive trimming of the frog allows it to dry out and shrink up; it eventually becomes very hard, and instead of being a cushion to break the concussion, when the foot strikes the ground, it is similar to a rock which has wedged in between the bars, giving the horse pain with each step.

Heavy horses with wide feet and horses raised on soft, marshy pastures usually have flat feet. The natural flat foot, although particularly liable to bruises of the sole, must be classed as a sound foot and must be distinguished from one that is flat as a result of disease.

On account of its shape, the natural flat foot is sometimes called "flare foot." The wall in such a foot wears away (or is trimmed away) at a more oblique angle than in the ordinary upright foot and it is therefore frequently necessary, in the preparation, to remove a part of the outer edge of the wall in order that the nails may be driven in the white line where they belong. 


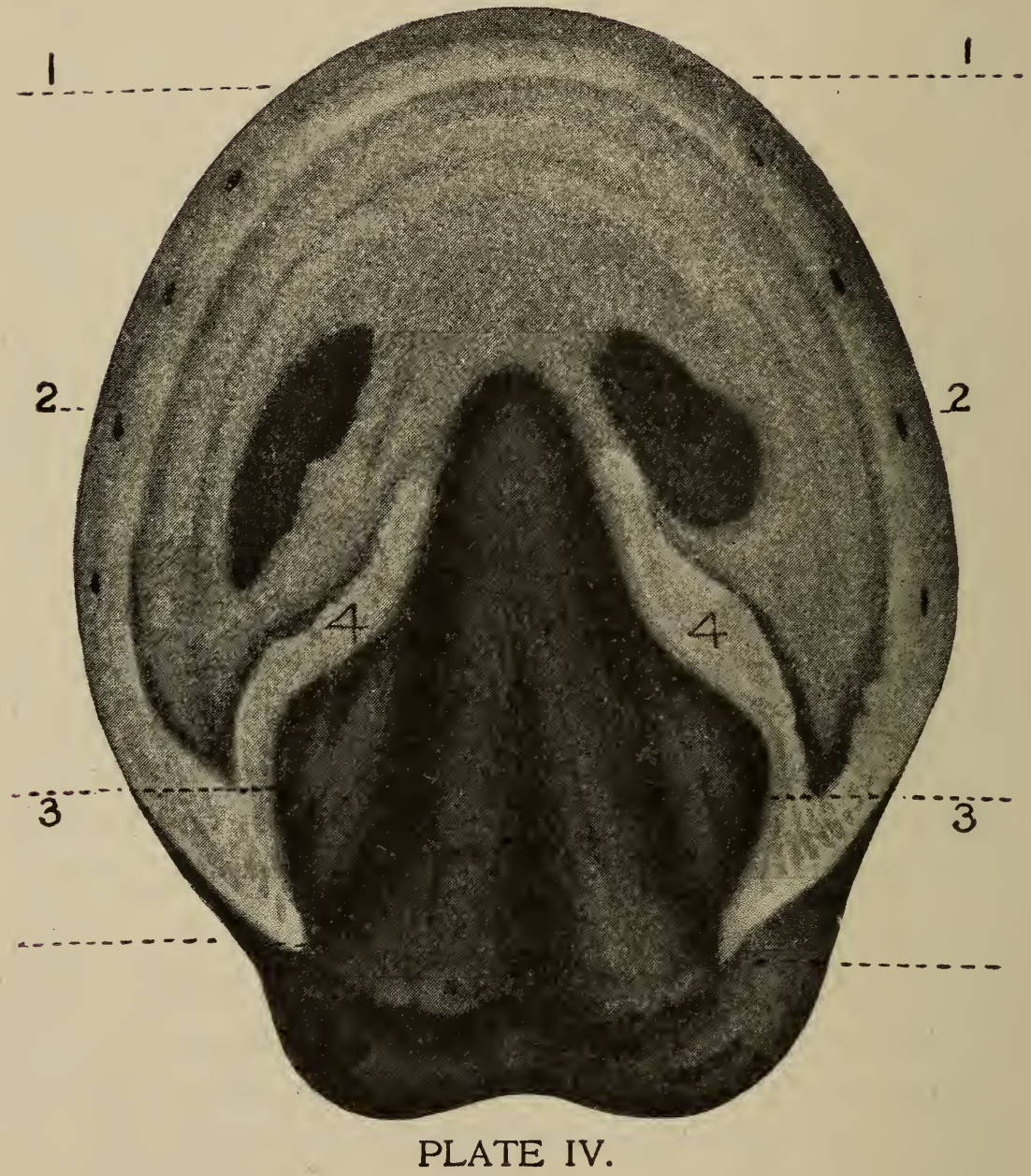

'Preparation of the Foot.

The foot ready for the new shoe.

I, Toe: 2, Quarters; 3, Heels; 4, Bars. 
In General: The foot should be prepared so that it will approximate as nearly as possible to a state of nature, and only such trimming should be done as is absolutely necessary for the purpose of fitting and securing the shoe. (See Plate IV.)

There are many cases where the feet are not level (the foot and pastern axes do not coincide) at the time the horse is brought to the shop for shoeing. As already explained. where the feet are not level, they show a condition of "broken in" or "broken out" when viewed from the front; or they may $b_{2}$ "broken back" or "broken forward." The latter defect is noted when the foot and pastern axes are studied from the side. This lack of levelness may be due to an uneven growth of horn since the last shoeing, the horse may have cast a shoe and one side of the wall broken away, or the horse may have been running barefoot for a consid. erable length of time and one side receiving more wear than the other side. The benefit derived by the shoer in making the several examinations mentioned is that he at once obtains a knowledge as to what part of the foot should be first taken down. After taking down the high side to correspond to the low side, he can then determine how much, if any, the low side can be lowered. In case the low side will stand taking down, the shoer removes the same amount of horn around the entire bearing surface. 
To determine the level of the foot, the shoer causes the horse to stand evenly on his feet and examnines the foot and pastern axes, both from the front and side. He should then raise the foot to a position for sighting over the bearing or ground surface; sight over each side separately, from the buttress to the toe, and note any irregularities which may appear in these two surfaces; now continue the plane of the quarter and heel on one side across or through the horny frog to the opposite side of the foot for the purpose of determining whether or not the two sides are in the same plane. This may be done with the eye by drawing an imaginary line, or by placing the smooth surface of the rasp on a level with the bearing surflace of the foot, as indicated by the line $e-f$, Plate 5 . To determine the level of this plane, draw an imaginary vertical line through the cleft of the frog, as shown by the line $c-d$, Plate 5. If the latter line $(c-d)$ is perpendicular (forming right angles) to the line $\varepsilon-f$, the plane of the foot is level.

Both sides may be in the same plane and the foct not level. In such a case the plane is canted. The line $e-f$, Plate 5 , represents a canted plane and it will be noted that it does not form right angles with the vertical line $c-\dot{a}$. The true or level plane will be found at the line $a-b$, which line forms a perfect right. angle with the line $c-d$. 


\section{Practical and Scientific Horseshoeing}

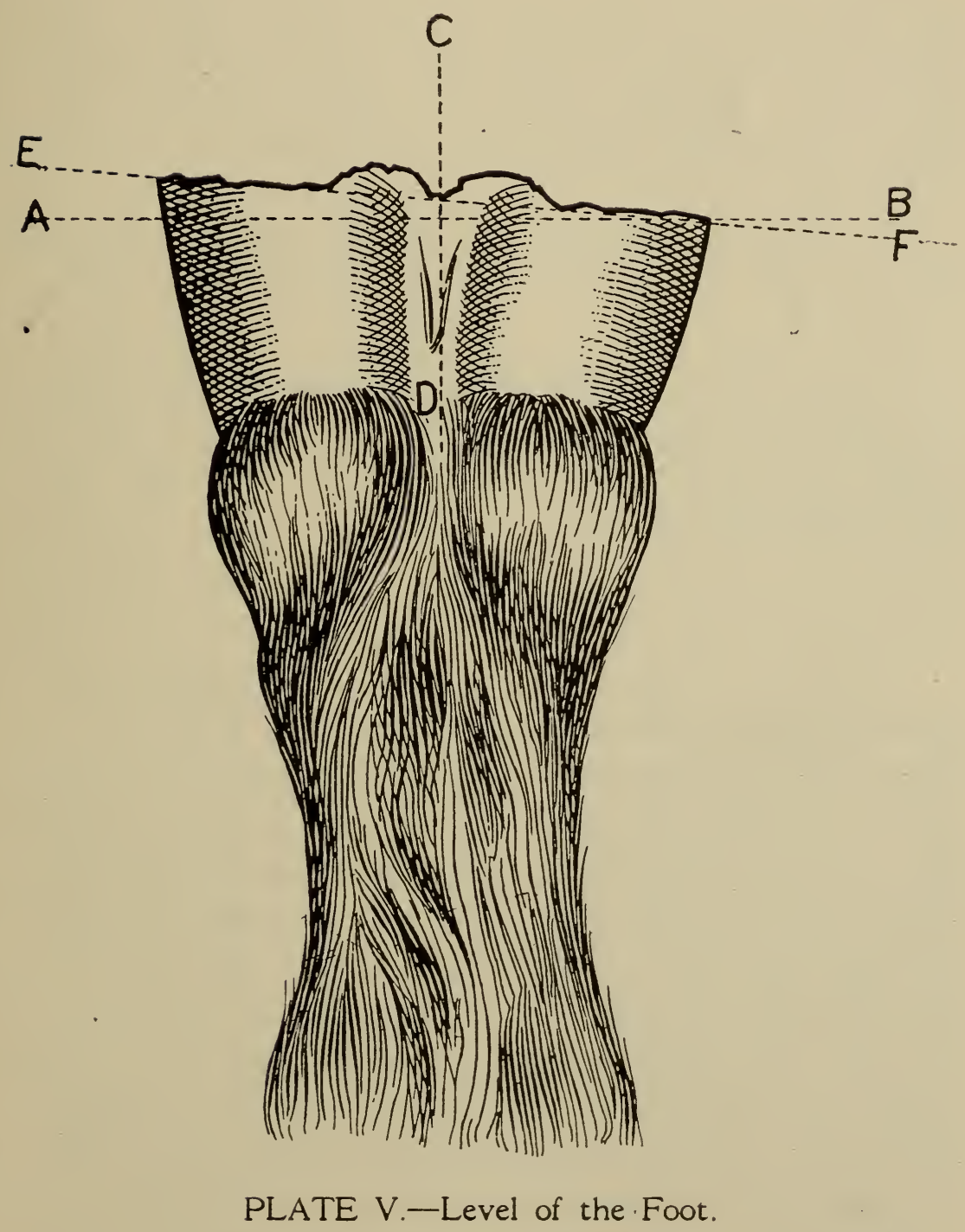


If the feet are not level, they are not balanced; the growth of the horn is uneven; the gait is affected by an improper breaking over of the foot; and there is an undue amount of strain on the ligaments and tendons of the foot and leg.

A horse having regular or perfect conformation of the feet and legs is balanced by an "absolute leveling of the feet."

The question of "balance" is further discussed in the chapter devoted to "Shoeing for Gaits," and it should receive the most careful attention of every person reading this manual.

\section{The Shoe.}

When horses are in constant use, it is necessary to prevent the too rapid wear of the hoof. The modern shoe, beyond all question, is the best means to accomplish this result, although it somewhat interferes with the natural contraction and expansion of the font. When shoes are left on the feet for too great a length of time, corns and other ailments result. Ordinarily a shoe should be renewed once a month. The heavier the shoe, the greater the labor of the horse. Hence, except in special cases, the lightest shoe that will last about four weeks is the best shoe. Shoe plain, without calks, if conditions will permit.

Calks are a detriment to keeping the feet in a sound 
and healthy condition. When calk shoes are used, the horny frog is so far removed from the ground that it does not bear weight as Nature intended. 'The frog, when it is allowed to bear weight, assists the elastic structures in breaking the shock when the foot strikes the ground, and also in the circulation of the blood through the folot.

When it is necessary to use calk shoes, I would advise the use of the bar in preference to the open shoe, providing that the lateral cartilages are in normal condition. With the bar shoe the frog bears weight, thereby reducing the concussion and increasing the blood circulation. The proper circulation of the blood in the foot stinulates the growth of horn and keeps the font in a healthy condition.

The shoe should carefully follow the form of the foot. If the wall of the foot is broken away, the shoe follows the original outline (shape) of the foot. The shoe should fit the outline of the foot around the toe from the bend of the quarter on one side to the bend of the quarter on the other side, and from the bend of the quarters back to the heels it should gradually extend beyond the wall to about one-eighth of an inch at the heels. The shoe extends beyond the wall from the quarters back irw order that the bearing surface of the wall at that point may be allowed to slide outward and inward over the shoe in expansion and contraction 
of the foot. The shoe should rest evenly on the lower border of the wall, white line, and just touching the outer edge of the sole; and it should be wide enough at the heels to cover the buttress. It should be properly concaved to prevent excessive sole-pressure.

In case of contracted heels, fit the shoe a trifle fuller at the heels. If one heel only is contracted, fit the shoe fuller on the contracted side to support the quarter by a larger ground surface, to give greater expansion, and to assist in the balancing of the foat.

In shoeing a foot with a pointed toe, fit the shoe. a trifle full on either side of the toe to assist in the proper breaking over of the foot. This also gradually trains the wall to grow into normal or symmetrical shape. The hoof is like clay in the hands' of the potter, and can be moulded to grow into almost any shape desired.

In case the feet are in such condition that it is impossible to obtain a level bearing surface, fit the shoe full on the low side and leave the heel of the shoe thickened; the heel of the shoe on the high side being thinned as is done in normal cases. A small side-calk may also be placed on the low side, near the toe. Use of the side-calk would be limited to cases where the thickening of the heel is not sufficient to bring the foot into a level position. This method of fitting the shoe is to make up, partially or wholly, for the deficiency 
of horn on the low side and to equalize the weight on the two sides, and to induce a proper breaking over of the foot. It also favors an even growth of horn. which brings the foot into normal condition.

$$
\text { Toe- and Side-Clips. }
$$

Toe-clips are often necessary to assist the nails in retaining the shoe in place. When calks are used, a greater strain is placed upon the nails than is the case with the plain shoe. The clips should not be too large or deep-seated. The seat for the clips should be just deep enough to allow for the thickness of the clip and no more. Deep-seated clips are liable to cause presiure on the sensitive structures and set up an inflammation. Side-clips are convenient when conditions are such that toe-clips can not be used.

\section{Hot Fitting.}

The fitting of a hot shoe to a foot is injurious and should by all means be avoided. The horn fibers of the hoof are unquestionably conductors of heat. By applying a shoe hot enough to cause smoke when it comes in contact with the horn, heat is transmitted to the sensitive structures, thereby setting up an inflammation and absorbing the natural moisture of the horn structures. This leaves the horn in a dry and brittle 
condition, which has a tendency to cause the foot to contract.

Cold-fitting is taught and practiced throughout the American Army and in the armies of other countries. The results attained are eminently satisfactory.

\section{Nailing.}

In considering the subject of nailing, it might be well to mention the opening of the nail holes in the shoe. The stability of the shoeing depends greatly on having the holes opened the proper size and at the correct angle. In size and shape the holes should correspond to the shank of the nail near the head, so that when seated in the crease of the shoe they will fill the holes snugly, or without any piay. If the nail holes are too large or of an improper shape, the nails not fitting them properly, there will be more or less friction of the shoe on the shank of the nails and the shoe soon becomes loose and finally drops off, many days in advance of the time when reshoeing would be advisable. The hole's should be opened at an angle corresponding to the slope of the wall at each individual point where the nails enter the hoof. It is well to remember that the slope of the wall at the quarter is greater (more upright) than at the toe. and therefore these nail-holes should be opened at a greater angle.

If the slope of the nail holes is not as great as the 
slope of the wall, the nailing is shallow and insecure

In obtaining the angle of the nail holes, it is preferable to pritchel from the upper surface of the shoe first, while the proper size and shape of the holes would be made by completing the pritcheling from the ground surface of the shoe.

By driving nails into the wall of the foot some of the horn tubes are destroyed, and the higher the nails are driven the greater the injury to the wall. Nails should therefore come out at a height just sufficient to hold the shoe-ordinarily not exceeding one inch-and in order to damage the wall as little as possible. both the size and the number of the nails should be as small as will accomplish this object.

The outside of the white line is the correct place to start the nails, and shoes should be fitted with this end in view. Nails, this started, come out evenly on the wall, are low and at a strong angle.

To the experienced shoer, the feel and the sound of the nail and the amount of force required in driving are important guides.

High nailing destroys more horn than is necessary for securing the shoe to the foot, and after a few shoeings the wall is filled with holes, which, in addition to being unsightly, greatly reduces the strength of the hoof.

We will take a case of a sound healthy foot in 
which the average growth of horn is about threeeighths of an inch per month. The first shoeing we drive the nails to a height of one and three-quarters inches; at the second shoeing we remove three-eighths of an inch of surplus horn and drive our nails threeeighths of an inch above the previous nailing; continuing this high nailing. one shoeing after another. until the hoof has grown enough to remove the first line of nail holes, we find several lines of nail holes in the wall, and the wall itself considerably weakened. By driving the nails to a height of three-fourths of an inch at the first shoeing and keeping them at the same height at each succeeding shoeing. we find that at the third shoeing we have but one line of old holes in the wall. In other words, we have removed sixeighths of an inch of horn in the second and third shoeings, and six-eighths of an inch being equal to three-fourths of an inch (which was the height of the first line of nails), it is evident that the first line of nail holes no longer appears on the foot.

The best nail on the market is the cheapest nail to use. They are easier and safer to drive, less danger of pricking a horse, less trouble on account of looseness and casting of shoes, and therefore keep your customers satisfied with your work. 


\section{Clinches.}

The clinches should be of uniform size, strong and smooth. The size of the clinch should be a trifle longer than the width of the nail where it breaks through the wall. In order to insure a strong and smooth clinch, file a slight groove in the wall under each nail point, to form a seat for the clinch. With the black and hammer, turn the clinch down and set it into the groove flush with the surflace of the wall. Very little rasping is necessary in order to smooth them. 


\section{CHAPTER IV.}

Gaits, Balance, Shoeing to Confirm or Altek Gaits, Faults in Gaits and Shoeing to CoRRECT SAME, THE MAKING OF Special Shoes FO: GaITS.

In shoeing horses for the purpose of confirming or altering gaits, it must be remembered that there are almost as many variations in gaits as there are horses, and that methods which are suitable in one case may be unsatisfactory in another. There are certain important principles, which, properly applied, will be of material assistance in gaiting the majority of horses. Shoeing alone will not always accomplish the desireil end, but it always helps. 'To shoe a horse so that he will be properly balanced and will travel squarely requires skill, patience, and a thorough knowledge of the construction of the feet and limbs.

It is always best to start with mild corrective methods, gradually increasing to a more severe treatment until the desired result is accomplished; otherwise injuries may result from overtaxed, strained, or ruptured tendons and ligaments.

In this chapter an endeavor will be made to give the reader a thorough description of the principles of the preparation of the feet, styles and fitting of the 


\section{Practical and Scientific Horseshoeing}

shoes, which should be applied in the majority of cases.

'The shoer, having once learned the principles of shoeing to correct faults in gaits, is able, by close observation of each case, to apply suitable methods of correction.

The principles of shoeing to correct faults in gaics are :

I. Proper balance of the feet.

2. Proper breaking over of the feet.

3. Proper forward and backward extension of the leg.

4. The legs and feet extended in a straight line or vertical plane.

5. Short toes induce high action and a greater backward extension.

6. Long toes induce low action and a greater forward extension.

7. More is accomplished by skillful preparation of the feet than by the use of extraordinary shoes.

The gaits which we will consider are the walk, trot, gallop, pace, and singlefoot.

The Walk.-At the walk, the horse lifts one foot at a time, in diagonal sequence, as: left front foot followed by right hind foot, and plants them in the same order.

The Trot.-The trot is a diagonal movement, in 
which two feet leave the ground and again strike the ground at the same time, as: the left front foot and the right hind foot.

The Gallop.-The gallop is a gait in which the horse springs into the air from one front foot and has all four feet off the ground at once. The diagonal hind foot is the first to strike the ground, then the other hind foot, next the front foot opposite the one from which the spring was made, and last the foot used for the spring.

Animals that are frequently used at the gallop should carry as light a shoe as practicable.

The Pace.-The pace is a lateral movement--that is to say, a movement in which two feet on the same side leave and strike the ground at the same time. A confirmed pacer can very rarely be converted to the trot by shoeing alone, it being generally necessary to use hobbles, uniting diagonally a front leg and a hind leg.

The Singlefoot.-This is an irregular gait, distinguished by the hind legs moving in the order for the fast walk and the front legs in that of a trot, each font striking the ground singly. The footfall has a characteristic rhythm, which, once learned, will be easily recognized, even in the dark. 


\section{Balance.}

The foot and leg which enjoys perfect equilibrium is balanced.

By balance of the foot is meant symmetry of ontline, or having the same amount of foot on each side of the median line as seen from the front in the fore leg and from the rear in the hind leg.

The median line of the perfect fore leg falls from the point of the shoulder to the ground, cutting the forearm, knee, cannon, pastern, and hoof into two equal parts. For the perfect hind leg this line starts at the buttock joint and cuts the hock, cannon, pastern, and hoof into two equal parts.

In horses with poor conformation the median line may fall on either sicle of the pastern and foot axes. In case of a "toe out," it is found to fall to the inside of the center of the toe, and the foot breaks over at that point. In case of a "toe in," the opposite condition and effect are found.

Hence, in faulty conformation of the legs or feet, there is a lack of balance and an improper breaking over. The foot usually goes in the direction in which it breaks, as in "toe out" the foot breaks over on the inside of the toe and is extended forward with an inward swing or curve. With regular or good conformation the fol breaks over at the center of the toe 
and is extended forward in a straight line and without lateral deviation.

By balance of the foot and leg in motion is meant an equal extension to the front and backwards and without an outward or inward swing.

We might compare the leg and foot with a piece of machinery, finding friction at every point where there is an improper adjustment of the parts.

For the freest and easiest gaits, the leg and foot must be balanced; but in many cases the conformation of the horse is such that a balance of the gait is most difficult to obtain. However, all shoeing should be with the idea of obtaining as true a balance as is' permissible by the particular class of shoeing made necessary in the correction of individual faults in gaits.

\section{Confirming or Altering Gaits.}

The Trot.-If a horse is inclined to singlefoot, and the trot is desired, shoe with heavy toe-weights in front. For the hind feet use a light shoe, with the toes rolled and the heels slightly thickened.

Preparation of the Feet: Leave the toes a trifle long in front, and shorten the toes on the hind feet.

The action of the toe-weight on the gait is that it gives greater forward extension and low action. The preparation of the hind feet--together with the light 
shoe, toes rolled and heels thickened-induces a more rapid breaking over and higher action.

The Singlefoot.-To confirm this gait, shoe with heel-weights in front and a heavy side-weight shoe behind.

Preparation of the Feet: Toes shortened for the front feet and left long on the hind.

Action: The heel-weights cause the horse to fold high, greater knee action, and a greater backward extension with less forward extension. 'The side-weight's behind somewhat delays the breaking over of the foot and causes an outward swing of the leg.

To Alter the Pace.-In cases where horses are inclined to pace and the trot is desired, use mediumweight shoes in front with the toes well rolled, or a roller-motion shoe. The toes of the feet are shortened. For the hind feet normal preparation is made, with light-weight shoes thickened at the heels.

A confirmed pacer can rarely be converted to the trot by shoeing alone; use is made of hobbles, uniting diagonal feet.

\section{Forging.}

Forging, or clicking, is a fault in gait at the trot, the toe of the hind foot overtaking and striking the bottom of the front foot; the front feet are slow in breaking over and leaving the ground, and the leg has 
a greater extension backward than forward. The hind feet break over too rapidly and their forward extension is greater than the backward.

The causes of forging are: Faulty conformation; horses with short bodies and relatively long legs; horses with the front or hind feet set too far under the body. Leg weariness, a condition caused by debility or over-exertion. Improper preparation or shoeing that tends to slow the action of the front feet; as feet with toes too long or heels too low; shoes too long or too heavy. Preparation or shoeing that tends to increase the action of the hind feet: as feet with toes too short or heels too high; shoes with heel-calks and no toe-calk. Rough ground and poor horsemanship; the reins held too loosely, the horse not being kept up to the bit.

To correct the defect by shoeing, the object of the shoer is to quicken the action of the front feet and to slow the action of the hind feet, or to increase the forward extension of the front feet and decrease the fritward extension of the hind feet.

It should be remembered that forging and interference are common to young horses when first shod and put to work. The muscles are soft and undeveloped, the animal tires easily, is awkward in his movements, and not confirmed in the gaits. In such case:s use a light shoe and adopt the mildest corrective method 
which will prevent the defect in gait. As the animal ages, his muscles become.s larger and stronger, he loses the awkwardness in gaits, and has acquired a balance in movement. This development, conformation being good, as a rule eliminates the necessity for special shoeing.

I will give several methods for shoeing to correct forging, with explanations:

First Method.-Shorten the toes of the front feet as much as they will reasonably stand and leave the heels a trifle high. For the hind feet, leave the toes long and lower the heels. Use a light machine-made shoe in front; the heels of the shoe just covering the buttress and finished with a long bevel from the ground surface, and the toes rolled to their full extent. For the hind shoes a heavier shoe should be selected; the heels of the shoe are left long (extending back of the bulb of the frog from about one-half to three-fourths of an inch); the toes of the shoes are squared and fitted, so that about one-half of the thickness of the wall projects over the shoe.

In shortening the toes and leaving the heels high in the front fleet, we lessen the labor of the flexor tendons and induce a more rapid breaking over of the feet Lowering the heels and leaving the toes long in preparing the hind feet increases the labor of the flexo: tendons and delays the breaking over of the feet. By 
shortening and making a long bevel on the heels of the front shoe, the toe of the hind shoe is prevented from grabbing the heels of the front feet and thus puiling: off the shoes. 'The toes of the front shoes are rolled to assist the foot in breaking over quickly and giving higher action. The toe of the hind shoe being square, and the wall extending beyond the outer edge of the shoe, prevents the disagreeable noise made if the feet should occasionally strike; the heels of these shoes are long, and the shoe heavier in weight, to furtiner increase the labor of the flexor tendons and aiso retard the breaking over of the foot. The action of the foot is low, with a shortened forward extension.

Second Method.--Get the feet absolutely level; use a fairly heavy toe-weight shoe in front and heavy sideweight shoes on the hind feet, the weight and trailer being on the outside.

'The effect of the toe-weight on the action is to in-crease the forward extension, with low action. The side-weight and trailer on the hind feet induce an outward swing of the foot and leg, thus giving the fore feet more time for breaking over and getting out of the way.

Third Method.-Prepare the feet as recommeniled in the first method. Front shoes should be light in weight, fitted short at the heels and with short heelcalks inclined well to the front, toe thoroughly rolleil. 


\section{Practical and Scientific Horseshoeing}

Hind shoes should be heavy in weight, small toe-calk set well back from the front edge of the shoe, toes squared, heels long and side-clips on each side between the first and second nail-holes.

This method should be used only when the other methods have failed to correct the fault in gait, as the feet are thrown so far out of their natural positions that the ligaments and tendons are apt to be aftected in time by the heavy strain placed upon them.

Fourth Method.-In case the hind feet are short, due to breaking or wearing away, we might use an extension toe to lengthen the ground surface. (See Figure Io, Plate 6.) When calks are necessary to prevent slipping, use heel-calks and short quarter-calks, welded on the web of the shoe between the first and second nail holes for the front feet. For the hind feet the usual style of calks can be used, the latter being a trifle shorter than the toe-calks.

\section{Scalping.}

Scalping is closely allied to forging. The forward and backward extension of the limbs are not equalized. It differs from forging in this particular: in the former the toe of the front foot strikes on the front surface of the wall, coronet, or pastern of the hind foot; while in the latter case the toe of the hind foot strikes on the bottom of the front shoe. 
Remedies: Where speed is not considered, use the same methods of correction as for forging. Where speed is a factor, shoe with the toe-weight in front and a side-weight or normal shoe behind.

\section{Cross-firing.}

Crass-firing is a fault common to the gait of a pacer, the hind feet swinging under the body and striking the diagonal front feet.

Remedies: Use a heavy side-weight on the outside of the hind feet, the toe squared, weight creased a considerable distance from the outside edge of the shoe, the shoe fitted so that a portion projects beyond the edge of the wall from the toe to the third nail on the quarter. (See Figure i I, Plate 6.)

Action: To prevent an inward swing of the leg.

An L-shaped calk or grab welded on the outside of the shoe is frequently of benefit in a case of crossfiring. The calk should extend from the center of the toe to about the third nail hole on the outside. The height of the calk should be not more than threesixteenths of an inch. This prevents the foot from slipping or twisting at the moment of breaking over.

\section{Interfering.}

A horse interferes (strikes) when he is in motion by hitting any part of a limb with the opposite foot. 


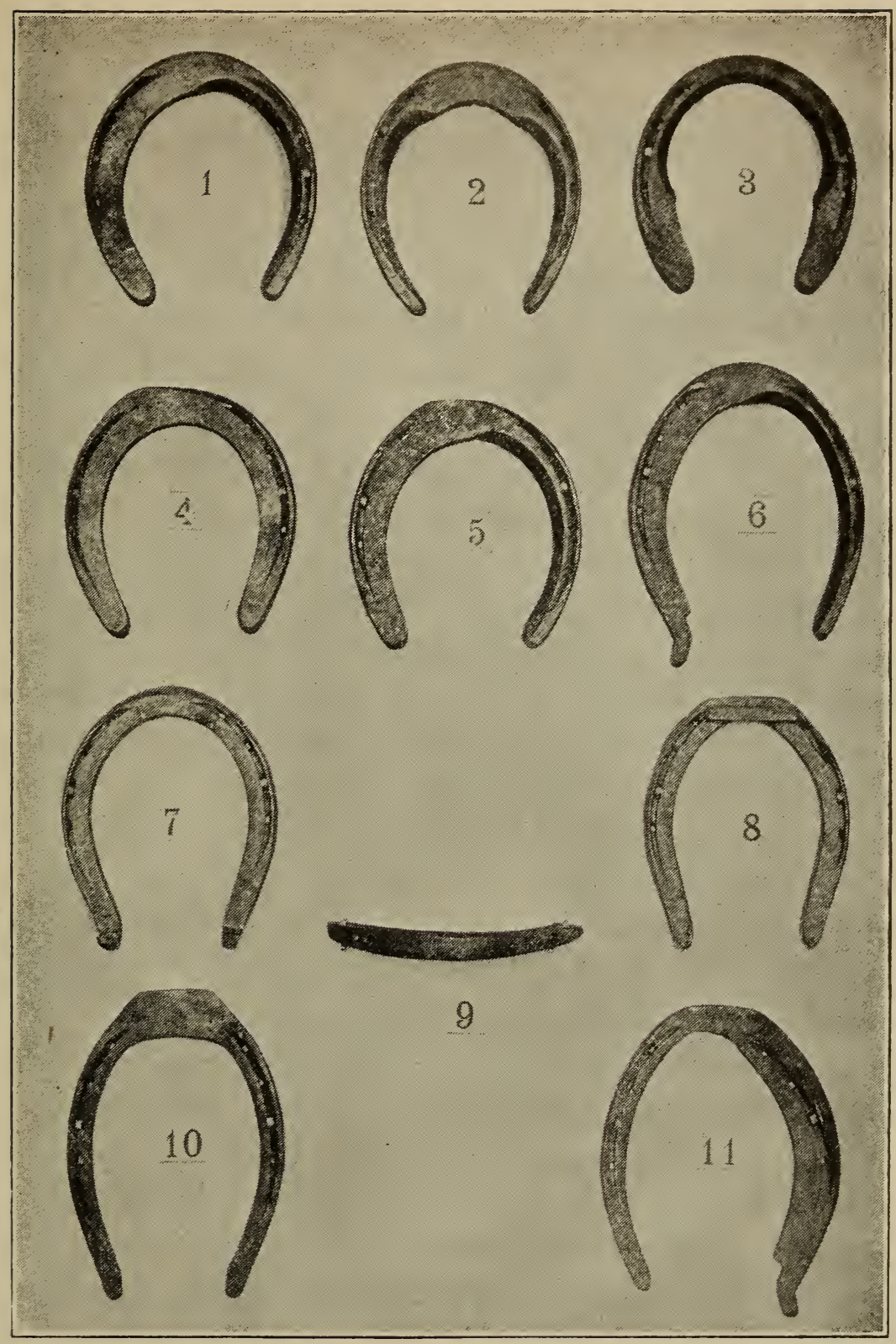

PLATE VI.

I, Front Side Weight; 2, Toe Weight: 3, Heel Weight: 4, Extension Squared Toe: 5 . Combination of Side Weight and Extension Squared Toe: 6. Hind Side Weight; 7. Front Forging: 8, Hind Forging: 9. Side View of Roller Motion; Io, Hind Extension Toe: I I, Cross-Firing. 
Since this fault leaves evidence by rubbing off the hair and even breaking the skin, it is an easy matter to determine whether one or both feet need correction.

Causes. - Poor conformation; fatigue; faulty or neglected shoeing.

Horses with good conformation and straight, upright limbs will not interfere if properly shod. Those that "toe out" often strike, because the clearance space between the limbs is reduced; while those that "toe in" usually travel wide. Straight-limbed horses with narrow chests also have a tendency to interfere. In order to correct interfering, the shoer should study carefully. the shoeing, the conformation, and the gait of the horse. The first step is to determine the exact part of the hoof that strikes. 'T'1ns may be readily, learned by chalking the inside of the wall and trotting the animal slowly. The chalk will be rubbed off from the exact point of contract with the opposite leg.

Inspect the shoeing for projecting clinches or ragged edges of the hoof, due to neglect. If the shoeing is of recent date, note if the shoe is too full. Then inspect the foot and see if the inside is too low or the ontside is too ligh (broken in). This fault bends the leg inward at the fetlock joint, starts the foot on a curve instead of a straight path, and thus lessens the clearance space between the legs.

Remedies: If the fault is in the shoeing or in the 
preparation of the feet, the remedy is apparent. If due to faulty conformation of the limbs, examine the gait very closely. Observe the breaking over of the feet and decide whether it breaks over the center of the toe; is the path of the foot carried in an outward or inward swing? Note the height of the stride.

With an improper breaking over of the feet, we find a defect in the gait-the feet are not extended in a straight line. Experience has taught me that in correcting the breaking over, we usually correct the fault in gait. Be careful in the preparation of the feet and use a shoe of as simple design as will accomplish the desired result.

We Will First Take Up the Interference of the Front Legs in Case of an Animal of Good Conformation.-The fault is frequently caused by improper preparation of the feet, such as leaving the outside high. The feet are not balanced for the reason that there is more foot on the outside quarter, the breaking over is at the inside of the toe, and the foot is extenter in an inward swing. Correction in this case is leveling of the feet and shoeing normal, the inside edge of the shoe and the clinches being carefully smoothed. In case we find that conditions are such that it is impossible to lower the outside to conform to the inside, then it is necessary to use artificial means to build up the low side. This may be accomplished by welding a 
light calk on the inside web of the shoe, near the tree, and thickening the heel on that side. The helel is thickened by drawing it to a feather-edge on the ground surface and leaving the upper surface as wide as possible in order to give good support to the wall. The height of the calk and thickness of the heel should be just sufficient to bring the foot and pastern axes in prolongation when the shoe is on the foot.

Animals Haring Pointed Toes Are Often Subject to Interflering. - This is due to lack of support for the foot, and in preventing a proper breaking over at the toe. The shoeing for this class of foot is: Level the feet; fit the shoe barely flush at the center of tile toe and a trifle full on either side of the toe back to the second nail holes. By fitting the shoe in this manner, we enlarge the ground surface, prevent the foot from rocking, give better support to the limbs, and indice a proper breaking over of the foot. We might further aid the breaking over of the feet by squaring the toe of the shoes.

For a Case of Toe-out, Due to Faulty Pastern Conformation.- In a case of this kind the breaking-nve: point is at the inside of the toe, and the foot is extended with an inward curve, frequently causing an interference of the limbs. Here again we find a laci: of balance and an improper breaking over of the feet. This case differs from those explained in that it is an 


\section{Practical and Scientific Horseshoeing}

imperfection of Nature and a more difficult case to correct. The conformation we cannot change, but the fault in gait common to this conformation can be intproved or corrected by careful preparation of the feet and fitting of the shoes.

When preparing the feet, we must not lose sight of the fact that they are not balanced nor breaking over properly at the toe.

Preparation of the Feet: Prepare the feet so as to bring both sides in one plane, the highest point (or greatest length of wall) being at the position of the nail nearest the toe on the inside, and the lowest poin! at the outside heel. Note that in this preparation the plane of the foot is canted to the true axis of the foot and pastern. By leaving the inside high we mor: nearly approach a balance and also induce the foot to break over near the center of the toe.

Shoeing: Use a light-weight front or hind shoe; toe squared and with an angular extension on the inside (see Figure 4, Plate 6), and the outside rolled; the inside of the shoe is fitted full from the tore to the first or second nail hole and close from that point back to the heel; the inside of the shoe should be well rasped and smooth; the outside quarter of the shoe $i$, fitted normally. A side-weight shoe, with the weight on the, inside will often help to correct a case of this kind, and may be used in combination with the 
extension and squared toe. (See Figure 5, Plate 6.) Action of the Weight: The weight helps to balance the foot in motion, and decreases the inward curve of the foot.

Narrow Chest and Limbs Close Together. - The clearance space between the limbs is so small that when the animal travels on uneven ground, or is the least bit tired, he will often interfere.

Remedies: Level the feet; use a side-weight shoe with weight on the inside and the toe slightly squared; have the shoe well rasped and smooth on the inside. If this does not give the desired result, you can use a light machine-made shoe with a small calk welded on the inside web, near the toe, the heel being thickened a corresponding amount. The latter method causes a breaking over of the foot to the outside of the toe and also increases the clearance space between the limbs by bowing out the fetlocks. It is a decidedly extreme method of correction and should only be used as a last resort, as the ligaments and tendons are liable to injury on account of the excessive strain thrown upon them!

We will now consider the interference of the hind legs :

Toe-out.-The foot breaks over at the inside of the toe and is extended with an inward swing, often resulting in serious interference of the limbs. Three 
methods will be given for the correction of this fault in the gait for horses having this class of conformation:

First Method: Frepare the feet so as to bring both sides in one plane, the highest point (or greatest length of wall) being at the position of the nail nearest the toe on the inside and the lowest point at the outside heel. Here we have a canted plane. Use a light machine-made shoe with the toe squared and extending slightly beyond the wall on the inside from the toe to the second nail hole and from that point fitted close back to the heel. The inside of the shoe is well rasped and smooth, while the outside of the shoe follows the outline of the wall with normal expansian at the hee!. A trailer on the outside heel should also be used.

Second Method: Prepare the feet the same as given in the first method. Use a side-weight shoe and trailer, the weight and trailer being on the outside.

Third Method: Prepare the feet as specified in the first and second methods. Shoe with a combination of the two methods previously given; that is, a side-weight and trailer on the outside, and the toe squared; otherwise the shoe fitting the foot as described in the first method.

Narrow Behind and Limbs Close Together.-Here we have very little clearance space and the horse interferes at the slightest provocation. We will give two methods for the correction of this fault in gait. 
First Method: Level the feet. Shoe with a sideweight and trailer on the outside. This induces an outward swing of the leg.

Second Method: Level the feet. Use a lightweight machine-made shoe with a calk welded on the inside web, near the toe, the inside heel of the shoe being thickened to correspond with the height of the calk. Here we are putting an unusual strain on the ligaments, and the method is recommended for use only when the first method has failed.

\section{Stumbling.}

The horse stumbles in breaking over, or just after breaking over, as a result of not raising and carrying a foot high enough to clear the ground. Horses stumble more frequently with the firont than with the hind feet.

Causes.-Poor conformation; horses with light fore quarters and heavy hind quarters. Weakness; during convalescence from severe sickness, or as the result of a strain of a leg muscle. Fatigue; induce 1 by long driving or riding, or by drawing heavy loads. Improper preparation; toe left too long. Improper shoeing; shoes too heavy or fitted too full at the toe. Laziness, particularly when going down hill. Rough ground and poor horsemanship.

Remedies.-The bearing surface of the foot must 


\section{Practical and Scientific Horseshoeing}

be levelled, the toe shortened, the shoe made light in weight and thoroughly rolled at the toe, and the thickness of the heels of the shoe slightly increased. This shoe induces more rapid breaking over.

\section{Paddling.}

Paddling is due to faulty conformation, the horse "toeing in."

The breaking over point of the foot is at the outside toe, and the foot is extended with an outward swing.

- Prepare the feet so as to bring both sides in one plane, the highest point (or greatest length of wall) being at the position of the nail nearest the toe on the outside, and the lowest point at the inside heel. This gives a canted plane. Shoe with an extension, squared toe, the extension being on the outside of the toe. A combination of the squared toe and side-weight shoe, with the weight on the outside, can also be used.

The squared toe corrects the breaking over, and the side-weight balances the foot in motion.

\section{Making of Special Shoes for Gaits.}

Machine-made shoes can easily be converted into weighted shoes.

Toe-weight Shoe.-Select a shoe of the desired size and weight, preferably a front shoe. Heat the 
shoe to a white heat, and with the hammer and creaser mark a line half-way between the crease and the inner edge of the shoe. This line, made on each side of the toe, extends from the heel to a point between the first and second nail holes; it is then carried obliquely to the inner elge. The creaser is held as in creasing the shoe, so that the cut when finished will leave a snow-shore bevel. The cut should begin obliquely at the toe, for the reason that a right-angled cut weakens the shoe at this point and allows it to break after much wear. (See Figure 2, Plate 6.)

Side-rereight Shoc.--The process in making is the same as given for the "toe weight" shoe, with the exception that the weight is removed from one side only, and the cut begins at the center of the toe. In the front shoe the heels are of normal length and finished in the usual manner. 'The weight on the hind shoe extends back towards the buttress as flar as possible without covering the frog. The outside heel is drawn about three-quarters of an inch longer than the inside heel and from the end of the buttress it is turned outward. This extension is called a "trailer" and serves to increase the rotary motion given by the weight. The inside heel is of normal length. (See Figure 6, Plate 6.)

Heel-reeight Shoe. - The process in making this shoe is the same as given for the other weighted shoes, 


\section{Practical and Scientific Horseshoeing}

except that the weight is removed from around the toe and on each side back to a point between the third and fourth nail holes. A front shoe should be used. (See Figure 3, Plate 6.)

F.rtension Square Toe.--Heat the shoe to a white heat and place it over the horn of the anvil and square or upset the toe. Then place the shoe on the face of the anvil and draw or thin the shoe on the desired side. (outside or inside of the toe), so that it extends over the wall. The opposite side is rounded off by hot rasping.

In turning the shoe from bar steel, crease well in on the web near the toe on the side where the shoe is to extend beyond the wall. (See Figure 4, Plate 6.) 


\section{CHAPTER V.}

\section{DISEAASES OF THE FOOT.}

\section{Detection of Lameness.}

Severe lameness is readily recognized, even when the animal is at rest. Distinct symptoms, such as pointing or frequent raising of the affected limb, are noticed, the animal's instinct leading him to place the injured foot in a position to relieve the pain.

In making an examination for lameness the animal, having free use of his head, should be led at a slow trot toward and from the observer. If lame in one fore leg, the head will nod (drop) when he steps on the sound leg, while it jerks up at the moment the lame one strikes the ground, and the stride is shortened on the lame side. Should there be lameness in both fore legs, the action is stilty (stiff); the steps are shortened and the feet kept close to the ground.

Lameness behind is detected by trotting the animal away from the observer, the croup being the essential part to be watched, since it drops with the sound leg and rises when the injured leg strikes the ground.

In all cases examine the feet thoroughly, iemoving the shoe when necessary.

Heat, pain, and swelling are always guides in the diagnosis of lameness. 


\section{Practical and Scientific Horseshoeing}

In making an examination of the foot for lameness, it is desirable to cut the clinches and remove the shoe by drawing each nail separately, closcly examining them for traces of moisture. Note the position of the holes where the nails entered the hooi. Clean off the sole with the knife. This done, more than usual care should be taken in following up any small prick or dark spot that may show itself upon the clean surface of the sole. Examine the frog in the same manner for traces of a puncture. A puncture of the frog is often most difficult to locate, as the horn fibers are softer and finer than those of the sole. An opening made in the horn fibers of the frog readily closes and leaves very jittle trace of having been punctured. One should also examine the condition of the horn at the seat of corns; note the shape of the heel (contracted or otherwise), and the appearance of the frog (clean or discharging).

Pathological shoeing is shoeing for the relief of diseased feet. The bar shoe is most commonly used, because it produces frog-pressure, which increases blood circulation and thus assists Nature's method of building up diseased tissue. Removing pressure means trimming the bearing surface of the foot in such a way that the shoe cannot cause pressure upon diseased parts. 


\section{Thrush.}

Thrush is a disease of the horny frog, caused by uncleanliness of the feet. The owner or porson in charge of the horse has failed to clean out rine feet at the daily grooming, or the horse has been allowed to stand in a wet and filthy stall. In this disease there is a dark-colored discharge of highly offensive odor.

Treatments: Clean out the feet and trim away the diseased part of the frog, so as to expose the seat of the trouble; all loose portions of the frog should be r. moved. Clean thoroughly by washing with an antiseptic solution; then thoroughly dry the foot and apply a drying powder of powdered alum, calomel, or copper sulphate. A leather boot may be used to hold the dressing in place. After all suppuration has ceaser?, pack the feet with tar and oakum and shoe with either the open or bar shoe. In case the heels are contracted, shoe as prescribed later for "contracted feet."

\section{Canker.}

Canker is a disease somewhat similar to thrush and often follows that disease. This disease affects both the sensitive frog and horny sole as well as the horny frog. T'here is a very offensive-smelling discharge from these parts; a spongy enlargement of the sensitive frog is found. It is generally believed that this disease is caused by a vegetable parasite, the devel- 
opment of which is assisted by filthy stables. It also often follows an injury which has exposed the sensitive structures of the foot, and in such cases it soon causes a separation of the soft and horny portions.

Treatment: That part of the frog or sole that has been under-run must be removed with the knife, and the canker exposed; the unhealthy growth is then touched with a red-hot iron, burning it off level with the surrounding healthy structures, care being exercised not to injure the sensitive portions of the loot. Next, wash clean, then dry, and apply the following powder: equal parts of sulphate of zinc, sulphate of iron, and sulphate of copper. Place over this a pad of oakum, and over all a leather boot. This dressing must be changed once a day-twice a day in bad cases; treatment is continued until a healthy growth of horn covers the whole foot. The horse can now be shod. Pack the foot with oakum and tar, and cover with a leather sole, which is held in place by the shoe.

If it is desirable to change dressings on the shod foot, a more convenient appliance to keep them in place is made in the following manner: Cut a piece of sheet zinc to cover about two-thirds of the sole and frog, the outer edge of the piece fitting under the shoe; cut another piece to cover the remaining third, and wide enough to lap over the first piece; the lap to run parallel to the cleft of the frog; then cut a strip about 
one inch wide to act as a keeper; the ends of this strip are pressed under the shoe, the strip passing across the foot from quarter to quarter.

\section{Dry Feet.}

Soften the hoofs by soaking in water, and then apply cosmoline or linseed oil. This should be done daily for a week or two. A thick paste of ground flaxseed and water, packed into the cavity of the foot between the branches of the shoe, or a packing of moist clay, will keep the foot soft. Contracted feet often follow excessive dryness of the feet.

\section{Contracted Feet.}

Contracted feet is an unnatural shrinking or narrowing of the feet at the heels.

Causes: Lack of exercise; lack of moisture; thrush; cutting out the bars; opening up the heels; cutting away the frog; concaving the upper and inner surface of the shoe, near the heels; nailing back of the bend of the quarters; continued use of heel-calks, and allowing the shoes to remain on the feet too long.

Treatment: Ascertain the cause and remove it if possible. The remedy is to get pressure on the frog. If the feet are extremely dry and hard, they may be softened by standing the animal in moist clay or in water. If the animal is to be used on soft ground, let 


\section{Practical and Scientific Horseshoeing}

him go barefoot, or shoe with the tip, otherwise one of the following methods: (a) Use the bar shoe in case the horny frog is not affected by thrush and is large enough to bear weight on the shoe. In using this shoe the cartilages must be sound. (b) The beveled-edge shoe might be used advantageously wherever the wali at the quarters is strong enough to stand the pressure caused by the bevel on the shoe. This shoe must be made with the greatest care, and the results of its use watched most carefully; carelessly made or carelessly used is apt to produce corns. Prepare the feet with the greatest care, beveling the heel (or buttress) from the outer margin inward towards the frog, or just the opposite to the bevel made on the shoe. This allows the lower border of the wall at the heel full support, or bearing, on the beveled part of the shoe.

\section{Corns.}

A corn appears as a reddish spot or discoloration of horn in the angle formed by the wall and bars, the result of bruising the sensitive sole or sensitive laminæ of the quarters and bars. It is more frequently found on the inside of the front feet than on the outside. The hind feet are seldom troubled with corns.

Corns are caused by concussion of the feet on hard roads, dryness of the feet, shoes fitted too short, contracted heels, shoes which remove the frog too far 


\section{Practical and Scientific Horseshoeing}

from the ground and thus preventing proper expansion of the foot, and by shoes left on the foot so long that the wall overgrows the heels of the shoe, thereby causing the shoe to press on the sole of the foot.

Treatments: Remove the shoe and examine the seat of the corn carefully, using the knife to pare away the discolored horn. If no pus or heat is found, the foot may be reshod, the shoer being careful to relievi: pressure over the diseased part. Pack the cavity with tar and oakum, using a leather pad to hold the pack in place. If the cartilages are in normal condition, a bar shoe may be used to good advantage.

If suppuration is found, the shoe must be left of: and the foot placed in a hot flaxseed poultice for several days, changing the poultices as they become cold When changing poultices, it is desirable to wash out the seat of the corn with a solution of creoline I part to 25 parts of water. Continue this treatment until all suppuration has stopped; when the horse may be shod, packing the feet and relieving pressure as explained above.

Puncture of the Sole and Frog-Pricks in Shoeing.

A puncture of the sole or frog is usually caused by a horse stepping on a nail, a piece of broken glass, or other sharp object. If the wound enters the soft 
structures of the foot, it results in lameness and the formation of pus.

Pricks in shoeing are of two kinds: first, when the nail is driven into the soft structures, and, second. when it is driven too close, causing a bulging of the inner layer of horn, which is forced in upon the sensitive lamina. In the first case the horse goes lame immediately; in the second case, lameness may not ar. pear for several days or weeks.

To detect a punctured wound of the foot, remove the shoe, examining each nail as it is withdrawn for traces of moisture. Then test with the pincers. When the sore spot is pressed, the horse will flinch.

Treatment: Open the wound and let out any pus that may have formed; wash out with a solution of creoline I to 25 , or of carbolic acid I to 20 . Unless the pus has a good outlet, it will burrow into the surrounding tissues and quittor or canker may follow. Moreover, there is always danger of tetanus in all cases of punctured wounds, especially in the feet. The germ of this disease is present in nearly all soils and is very liable to be carried into the wound upon the nail or other object. After the wound has been opened up and washed out, the foot should be placed in a hot flaxseed poultice, a fresh one being applied three or four times a day, and the parts washed out after each poultice, as in the first instance. The treatment should be 
continued until inflammation is reduced and the formation of pus has ceased. The hole can then be plugged with oakum and tar, the shoe reset, and the horse put to work. It is often desirable to use a "blind bar" shoe for this disease. The bar is welded on the shoe, from one quarter to the opposite side, so as to cover or protect the seat of injury.

\section{Quittor.}

Quittor is a running sore, situated on the coronet of the foot, with one or more tubes leading in a downward direction and discharging pus. It is caused by pricks in shoeing, punctures of the sole and frog, and by bruises or suppurating corns. There is a swelling at the coronet having a very unhealthy appearance. In most cases the horse is very lame.

Treatment: Find out, if possible, what has caused the quittor. If it is the result of a nail-prick or a festered corn, open it up on, the under side of the foot, allow the pus to run out, and then treat as directed for suppurating corns. If no nail-prick or corn can be found, treat the quittor from above, by injecting into the sinuses one of the following solutions: carbolic acid I part, water 20 parts; creoline I part, water 25 parts; bichloride of mercury I part, water 500 parts. 'This treatment should be continued for several days, at the end of which period, if the parts do not appear in a 
heaithier condition, inject into the tubes I dram of bichloride of mercury, well shaken up, in I ounce of water. This will cause a separation of the diseased walls of the tube from the healthy parts of the foot. Poultices of flaxseed meal assist this separation. Keep the parts clean, and wash out with carbolic acid or creoline as at first. If the sore does not heal under this treatment, a surgical operation by the veterinarian will be necessary.

\section{Toe- and Quarter-Cracks.}

'oe- and quarter-cracks are splits in the horn of the wall proper, the location of the crack determining the name applied to it.

These are caused by dryness of the feet, contracted feet, concussion, calked shoes, use of large nails, n.xils driven too far back towards the heels, and heavy shoes. Horses with thin quarters are predispised to quarcercracks.

These cracks generally start at the coronet and gradually extend downward to the lower border of the wall, often appearing as a deep fissure extending through the wall and causing a pinching of the sensitive structures. If the cracks are not deep, there is seldom any lameness.

Treatment: . If the horse is lame, he should be given a rest. Remove the shoe and soften the horn 
by poultices, or by standing in water for a few days; then cut away the hard overlapping edges of the fissure and thin the wall on each side, so that there will be no friction between the edges of the crack. As the wall grows down from the coronet, the upper end of the crack must be carefully observed to see that the new horn grows down strong and smooth. In time the crack will disappear at the lower edge of the wall. If the sensitive lamina have been exposed by this operation, the parts should be washed with a solution of creoline, I to 50 , and the wound should be dusted with acetanilid and covered with a pad of oakum held in place by a boot or bandage. In a few days a thin layer of horn will be thrown oit, covering the sensitive laminæ. The horse can then generally be put to work.

After a quarter-crack has been trimmed out, the horse should be shod with a bar shoe the wall beneath the quarter being cut away so that it will not come in contact wth the shoe.

In case of toe-crack, the operation is the same. In shoeing, the wall is cut away at the toe to prevent pressure. A bar shoe, rolled at the toe and with a clip on each side of the crack, is recommended. 'The bar shoe serves two purposes:

I. Ordinarily it is not possible to drive the proper number of nails on the side of the affected quarter, 


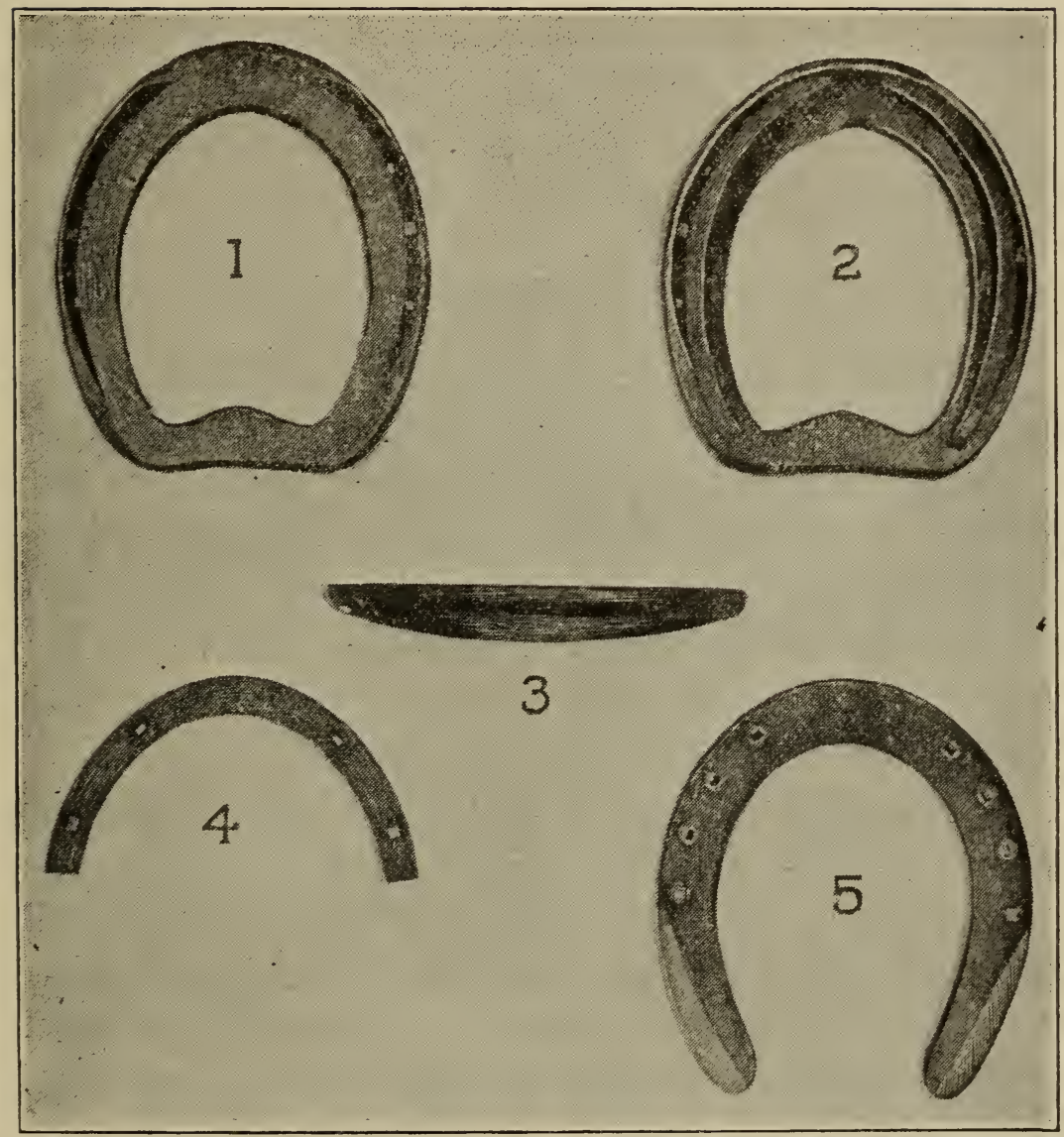

PLATE VII.

I, Bar Shoe; 2, Rocker Motion Bar; 3, Side View of Rocker Motion Bar; 4, Tip Made from Plate Steel; 5, Beveleil Edge. 
but the bar keeps the shoe in place on account of the firm nailing on the other side.

2. The bar gives frog-pressure and expansion. which are desirable, because quarter-cracks usually result from a weak and drawn-in quarter.

\section{Laminitis.}

Laminitis, which is commonly called founder, is an inflammation of the sensitive laminæ of the feet; ad joining structures are also at times affected. This disease is caused by concussion, exhaustion, overexertion, over-eating, drinking cold water when heated, and by eating of musty grain or liay. The $f$ st cause given is the most common. There are two forms of this disease: acute and chronic.

Ordinarily, in a case of inflammation, the blood vessels become enlarged and a surface swelling appears; but, when the sensitive laminæ are inflamed, the local veins, confined between the horny wall and the coffin bone, have no room to expand; in consequence, the pain of acute laminitis is very sharp and persistent.'

In laminitis of both front feet, the animal is excessively lame, moves with great difficulty, especially when starting, and appears as if the entire body were in a state of cramp; he stands with the lind legs drawn under the belly and the fore feet advanced, in order to 
relieve the painful feet of as much weight as possible. Occasionally he may be seen to sway backward, raising the toes and throwing the weight for a moment upon the heels of the front feet, and then resuning the originai position. If compelled to move, he raises the feet laboriously, not because the muscles are sore, as is sometimes supposed, but because, if ail four feet are not on the ground at the same time to bear the weight of the body, his suffering is increased. He will often groan with pain, and sweat will break out over the body. To diagnose a case quickly, the best method is to push the horse backward, when, if affected, he will elevate the toes and throw his weight upon the heels.

In some instances the animal will lie down upon his side, with legs stretched out, for hours at a time, evidently feeling great relief in this position; in other cases, particularly during the early period !of the disease, he will stand persistently.

Treatment: Remove the shoes from the affected feet; stand the horse in hot water for several hours each day, or, what is equally good and perhaps safer. apply hot flaxseed poultices, changing them every hour as they become cold. Another advantage of the :1se of poultices is that the animal may lie down during the treatment. The animal should be encouraged to lie down, as by so doing he finds great relief from the excessive pain; he should be turned loose in a well bed- 
ded box stall. After two or three days of this treatment, change to cold water, which can be applied either in the form of a foot-bath or by standing the animal in a running stream for five or six hours at a time. As soon as the pain has diminished, moderate exercise is beneficial; this may be gradually increased until the animal shows no further sign of trouble. If, after five or six days, pronounced symptoms of recovery are not apparent, apply a stiff blister of cantharides around the coronet, repeating the blister if necessary. In addition to the local treatment, nitrate of potash (saltpeter), in doses of 2 to 4 cunces, may be given three times a day. If the horse is constipated, give I quart of raw linseed oil.

After treatment, use a bar shoe, well rolled at the toe, and with thin heels. Use no toe-clips. Concave the upper web to remove sole-pressure

Chronic laminitis is permanent laminitis, resulting from one or more attacks of the acute form of the disease. In the chronic form, there is always inflammation, sometimes more, sometimes less, but never as severe as in the acute form. This varying inflammation affects the adjoining sensitive structures and interferes with their continuous, regular secretions. 'The coronary band becomes affected and consequently the growth of horn is not steady; this is shown by the growth rings on the outer surface of the wall. 


\section{Practical and Scientific Horseshoeing}

The interruption of the natural secretions of the sensitive laminæ results in irregular growth of the horny laminæ. In bad cases there is a rapid (false) growth near the toe that has not the ordinary amount of vitality, and seedy-toe frequently results. This extra growth also forces the coffin bone back from its proper position, and as the dove-tail attachment is not as strong as in natural growth, the weight of the animal forces the coffin bone down upon the sensitive sole, causing the ailment known as drop-sole. In very bad cases, the bone actually pierces the sole, and the animal is, of course, absolutely useless.

In a case of chronic laminitis, pay special care to the concaving and use a bar shoe rolled both at the toe and at the heel, called a rocker-motion shoe. This shoe produces a uniformily smooth breaking over, with but little jar.

$$
\text { Seedy-Toe. }
$$

Seedy-toe is a mealy condition of the inner wall of the hoof, the white line, and sometimes the sole.

It is often the result of chronic laminitis, or it may be caused by deep branding of the hoof, deep-seated toe-clips, and by an excess of sole-pressure at the toe The disease is most frequently found in the front feet.

Treatment: Pare the wall of the cavity until healthy horn is reached, and pack with tar and oakum. 
Stimulate healthy growth of horn by the application of cantharides blister at the coronet.

Use a bar shoe; no nails should be driven in the diseased part, but, instead, side-clips should be used, care being exercised that they bear only on the healthy horn:

\section{Sidebones.}

A sidebone is an ossification (turning into bone) of the lateral cartilage, frequently resulting from improper leveling of the foot, concussion, and loss of normal function of the horny frog and elastic structures. There is a hard, unyielding condition of the lateral cartilage, with or without lameness.

Treatment: If the horse is lame, the first step is to remove the shoe and level the foot; then let the horse stand in a tub of cold water for several hours a day, or apply, around the coronet, swabs kept wet with cold water. As soon as the fever has disappeared, clip off the hair over the sidebones, and blister with this ointment: biniodide of mercury I part, cosmoline 5 parts; mix thoroughly and rub in well. Tie up the horse's head so that he cannot reach the blistered parts with his lips, and keep him in this position for twentyfour to forty-eight hours. Then wash off the blister, using warm water and castile soap. The washing must be repeated every day until all the scabs formed 
by the blister have been removed. During this time keep the horse standing quietly in a clean and level stall. If after ten days he has not improved, firing. followe d by a long period of rest, may prove beneficial.

In shoeing a horse afflicted with sidelones, level the foot carefully. If the foot is affected mil onc side only, the affected side is liable to be contracted, because proper expansion has been prevented on that side. In this case, the web of the shoe should be widened sufficiently to extend out to where the normal ioot would be. A plain shoe with a rolled toe is recommended. Frog-pressure produces soreness, and must be carefully avoided. A calk shoe often provis berseficial by preventing the frog from coming in close contact with the ground. A bevel-edged shoe migint be used advantageously, as it spreads out the quarıers and heels. Contracted heels usually accompany this aisease.

\section{Ringbone.}

Ringbone is a bony enlargement, more or less prominent, situated upon either the os suffraginis or os coronæ, and it may also involve the articular cartilages. It may be caused by blows, sprains, jumping, fast work on hard roads, and faulty conformation.

Lameness is usually the first symptom, and diagnosis is assisted by feeling and comparison of the two 
legs. The enlargement is hard, painless on pressure, and the skin covering is movable.

Treatment: The foot must be pared perfectly level and a blister applied to the enlargement and repeated in two weeks if necessary. Perfect rest and quietude for four to six weeks are essential, or no beneficial results can be expected.

If the rest and blisters fail to remove the lameness, firing may be resorted to. Puncture firing in two or threc rows is often very effective. After firing, the seat of the injury should be blistered with biniodide of mercury I to 5, and the animal kept q'iet in a single stall for at least one month.

Shoe with medium-weight shoes, heels slightly raised and the toes well rolled; or with rubber pads and toes rolled to assist in the breaking over of the foot.

\section{Bone Sparin.}

Bone spavin is a disease involving the bones in the hock-joint and is 11sually manifested in a bony enlarge. ment, situated at the inner and lower part of the tarsus. It is caused by weakness, faulty conformation, severe strains, hard and rapid work, etc.

The appearance of this disease is usually accompanied by lameness, which in the early stages of the disease is noticed only when the animal is first moveu 


\section{Practical and Scientific Horseshoeing}

after a rest, and then the toe is generally placed upon the ground first. When standing, the animal often rests the diseased leg on the toe.

'The "spavin test" is sometimes useful in diagnosing spavin lameness. It consists in keeping the hock-jornt flexed for one or two minutes and then trotting rhe horse. If a spavin exists, lameness is very marked.

Treatment: The treatment of bone spavin is the same as that prescribed for ringbone.

Shoe with heel-calks, the toe being :ollei.

\section{Splints.}

Splints are bony enlargements, usually situated between the inner splint bone and the cannon bone, at their upper third. They occasionally occur on the outside of the hind leg. 'They are caused ly faulty action, or unequal distribution of pressure in the knee may throw an excessive load on the inner small metacarpas and cause rupture of the tissue affixing the small to the large metacarpal. The irritation produces growth of bone.

Soreness may or may not be present; when the splint is painful, the horse is lame.

Treatment: If there is lameness, give the animal absolute rest and apply a blister, composed as follows: biniodide of mercury I dram, cosmoline 5 drams. Re- 
peat in ten days if necessary. Shoe with rubber pads or the normal shoe.

\section{Coffin-Joint Lameness.}

A sprain of the coffin-joint results from slipping, stepping upon a rolling stone, stepping into a hole, etc. With this injury there is a shortened gait; rointing of the diseased foot; heat over the region of the coffinjoint; tenderness on pressure.

Treatment: Remove the shoe and give the animai complete rest; poultice the foot with flaxseed meal or stand the foot in a tub of cold water; if relief is not obtained in a week, apply a blister of biniodide of mercury around the coronet and heels, rubiving it in vell over the region of the heels.

A sprain of the coffin-joint, unless carefully nursed, may terminate in chronic navicular disease, in which the coffin-joint structures and the coffin bone itself become ulcerated. This disease is incurable.

After navicular disease has develuped, the heel of the diseased foot should be elevated by the use of a shoe with calks or with thick heels. The foot should be kept soft with foot-baths and poultices and a blister applied when lameness is especially marked. Whenever possible, keep the shoe off during treatment. 


\section{Practical and Scientific Horseshoeing}

Borved Tendons and Break-Downs.

Bowed tendons and break-downs are sprains of the flexor tendons and suspensory ligament, respectively. These conditions are often found in both front and hind legs, resulting from heavy pulling or sudden jerks The injury is easily recognized by the changed appearance of the parts, which become more or less swollen; the swelling usually extends from the knee down to the fetlock, and is accompanied by heat and soreness.

Treatment: Give the animal perfect rest. Hot or cold applications should be applied to the inju:ed parts. These applications should be in the form of bathing, or bandages saturated with water. Flanne! bandages must not be allowed to dry while in contact with the injured parts, as flannel applied wet shrinks in drying, and will cause pain. If, after the inflammation is reduced, the parts remain large and swollen, it may be found necessary to blister or even resort to firing. When the animal is ready for work, shoe with a light shoe; the toe should be well rolled and the heels thickened, or small heel-calks used. Rubber pads are good for cases of this kind. To strengthen or support the tendons when the animal is at work, dry bandages placed tightly around the legs over the injured tendons are an excellent thing, as they give additional support to the leg. 


\section{CHAPTER VI.}

\section{Miscelilaneous Hints.}

Shoes for Jumpers. - For the jumper the shoe should be of medium weight. The front shoes are fitted with a trifle less expansion at the heels than is the case in the use of normal shoes; the length of the heels is just even with the bearing surface of the buttress, and finished with a long bevel from the ground surface. Hind shoes should have small heel-calks to prevent slipping when taking the jump.

Shoes for Running Horses.-Shoes for running horses should be very light in weight, fitted close and short at the heels. The shoe is made preferably from rib steel, using a light grab at the toe.

Foot Adjuster.-The foot adjuster should form a part of the shop equipment, especially in shops where a high class of work is done. The gauge is more accurate than the eye, and in shoeing to balance the gait of a horse a fraction of an inch difference in the length of thel feet (or a couple of degrees difference in the angles) makes considerable difference in the gaits.

The Tip Shoe.-The use of the tip for contracted heels leaves the foot in more nearly a state of Nature than any other shoe. It is sufficient for light work. and is easily applied. It should be thin, only thick 


\section{Practical and Scientific Horseshoeing}

enough to hold the nails and not be flexible. An old shoe of the plain pattern, evenly worn, makes an excellent shove flor this purpose. Cut the heels of the shoe off at the fourth nail hole, leaving but three nail holes in a side. The tip may be made from bar steel. and $1 / 4$ by $1 / 2$ or $5 / 8$ is a desirable size. Two nail holes in a side are sufficient to hold a shoe of this description. The branches of the shoe hardly reach the bend of the quarter.'

Preparation of the Feet: If there is a considerable amount of horn to be removed from the toe, simply make a seat for the tip. In other words, remove the surplus growth of horn around the toe, and back toward the quarters as far as the shoe reaches. Fit the tip to the outline of the wall. After nailing the tip on the foot prepared for it, the heels are rasped down to a level with the ground surface of the shoe. This mannier of applying the tip keeps the foot in a true plane.

If there is no surplus horn to be removed from the toe of the foot, the branches of the tip should be thinned to give a more even bearing surface. This manner of applying the tip leaves the foot somewhat in a broken-back condition. 'The first method, in the writer's opinion, is the better of the two, as the feet stand at the prescribed angle (corresponding to the 
angle of the pastern), thus allowing a free and easy movement of the ligaments and tendons.

Shoeing with the tip shoe is undoubtedly the nearest to Nature it is possible to attain and at the same time protecting the hoof from wearing away too rapidly.

With the tip shoe the quarters, heels, and horny frog come in contact with the ground and the quarters are free to expand as Nature intended. The wall, being upright at the heels and quarters, does not break away very badly and the growth is about equal to the wear.

Shoeing of Horses Just Off the Range. - Young horses that are transferred from the ranch to the city should receive particular attention in respect to shoeing.

The horse is accustomed to running barefoot on soft ground, and changing to the hard, unyielding city pavement, together with the unaccustomed shoeing of the feet (generally being shod with toe- and heelcalks), soon causes trouble with the feet.

The feet of the young horse when first prepared for shoeing, and the lower layer of the sole and wall removed, are found to be very soft and flexible. The frog is well developed, the heels wide, and there is lots of moisture in the horn structure.

Shoeing with heel- and toe-calks raises the horny 
frog so far from the ground that it cannot bear weight, and the shock of the foot striking the ground is quite severe on the hoof and structures enclosed. Circulation of blood through the foot is diminished, due to loss of frog-pressure, and the horn rapidly dries out, becoming hard and brittle. Contraction of the hoof often takes place, and this is followed by many other ailments. To preserve the foot of the young horse as much as possible, the shoeing for the first six months should be such as will leave the feet as near as possible in the condition existing at the time the animal left the range:

Shoe with the bar shoe, plain if conditions will permit, and pack the feet with tar and oakum on every other shoeing. In this way the feet gradually accustom themselves to the changed conditions and the usefulness of the animal is considerably prolonged. Where the average usefulness of the work-horse in the city is about three or four years, it might be doubled with proper care of the feet.

Cleaning of the Ficet.-The horse's feet should , $c$ carefully cleaned each day. Manure and filth, if allowed to remain in the clefit of the frog and the commissures, soon decays and the result is a diseased condition of the horny frog. Another reason for cleaning out the feet each day is that in case a nail becomes 
lodged in the sole or frog, it may be discovered before the animal experiences any bad results from it.

The Horseshoer's Iournal.-Every progressive horseshoer should be constantly on the alert for improvements in methods, tools, materials, etc. The Horseshoer's Journal is the principal publication containing such information and it will be found of value to all shop-owners and workmen. The discussions on shoeing, etc., contained in that paper are interesting. and instructive.

Sizes of Shocs and Nails.-Nails run in sizes from twos for the Shetland ponies up to twelves for the Clydesdale and Percheron breeds. As a general ri:le, larger nails are used than is necessary to hold the shoe in place. It is the writer's opinion that a No. 5 nail is sufficiently large to hold Nos. I and 2 shoes, No. 6 nails for a No. 3 shoe, No. 7 nails for a No 4 shoe, No. 8 nails for a No. 5 shoe, and No. 9 nails for Nos. 6 and 7 shoes.

In the American Army the shoes for the cavalry and field artillery range in size from I to 5 , the latter size being seldom used. The nails range in size from a No. 4 to 7 ; fours are used in light-plate shoes; fives in Nos. I and 2 shoes; sixes in Nos. 3 and 4 shoes; sevens in No. 5 shoes, and occasionally in a No. 4 shoe.

We experience very little trouble with nails breaking or from cast shoes, although the ground traveled 
over is often very rough and rocky. By using the small nails, it is much easier to keep the wall of the feet in a strong condition.

Hoof Dressings.-Hoof dressing, when frequenily applied to the wall of the foot, one coat after another without removing the remains of the previous coat, is very injurious and the horn fibers under this treatment become hard and brittle. If a hoof dressing is to be used, it should not consist solely of grease, but should have mixed with it either wax or tar. It is the writer's opinion that hoof dressings are seldom necessary if the feet are otherwise properly cared for. $\mathrm{Na}$ ture has provicled a coating of fine horn fibers on the outer surface of the wall to prevent the natural moisture in the wall (which is supplied from the blood) from evaporating. I ikewise the horny sole and frog are covered with layers of lead horn which hold the moisture in the live horn. If when shoeing the horse this covering which Nature has provided is $\mathrm{n} n \mathrm{t}$ destroyed, there is no necessity of applying an artif:cial dressing.

The Bar Shoe.-The bar shoe is undoubtedly used more frequently and for a greater number of diseases of the foot than any of the pathological shoes. Its advantages over the normal shoe are:

I. The bar increases the strength of the shoe.

2. It gives frog-pressure and an increased cir- 
culation of blood through the foot to stimulate the growth of horn.

3. Fewer nails are required to hold the shoe in place, as the nails on one side assist those on the other side.

4. The bearing surface of the wall may be trimmed away for a considerable distance at any part, so that it does nolt come in contact with the shoe and without danger of the shoe being sprung.

For the benefit of the apprentice, I will describe the making and shaping of the bar shoe.

It is made from the machine shoe and the general fit and shape when finished are the same with the exception of the bar across the frog.

Select a machine-made shoe that is a size larger than the one that would ordinarily be used, and preferably a front shoe; a size larger in order that the heels shall be long enough to admit of turning the bar, and a front shoe on acount of its width and stock.

To Prepare the Heels of the Shoe before Turning in the Bar.-

(a) Scarfing: This 1s accomplished by holding the shoe on the face of the anvil (either surface on the face) and striking on the upper edge of the extremity of the heel, the hammer held at an angle of about 45 degrees with the plane of the upper surface. Thi.s 
will result in a bevel between the upper and lower surfaces of the heel about half an inch in length. Scarf the lother heel in the same way, except that the scarf is made on the opposite surface.

(b) Pointing the scarf (to in'sure a smooth weld) This is done by holding each heel in turn so tha it will rest at an angle upon the face of the anvil near the heel, and striking on the upper edge at the end. (This is the same position and accomplishes the same result as pointing the heels of the plate and normal shoes after drawing.)

To Turn in the Bar.-- Hold the shoe with the tongs at or above the toe; place the inside edge of the heel to be turned on the point of the horn, the quarter nearly horizontal, with one inch or an inch and a half projecting over the horn, depending upon the length of the bar required.

Strike on the upper edge of the portion projecting over the horn, lowering the hand as the bend progresses, and turn in the desired length at a right ans ${ }^{1}$.

The length of the bend should be a little more than one-half the length of the finished bar, as the ends must overlap for welding. Turn the other heel in tne same manner.

To Prepare the Bar for Welding.-Close the shoe bodily until the scarfed points overlap and then hammer the points down until they fit closely, leaving no 
space for coal dust to accumulate. It will be notticed that the overlapped ends approximate twice the thickness of the web of the shoe.

To Weld the Bar.-Place the bar in the fire and heat to a welding heat, tilting or rocking the shoe forward and back to insure an equal heat on both sides. When the proper heat has been obtained (fluxing), place the bar on the face of the anvil and strike a fcw light blows on one point, then reverse the shoe and strike on the opposite point. This will bind the points together.

Reheat the bar to the welding heat and, taking the same position, complete the weld by heavier blows, reversing the shoe so that both sides will be flattenerl. After the weld is completed, the bar is shaped by holding one corner on the point of the anvil and striking on the center of the bar and then reversing. This will set the center of the bar forward, give it the correct. shape at the heels and prepare it for beveling. The upper surface must be hammered down (beveled) from the outer edge of the bar to the point, thus forming a cradle for the frog.

Fitting.-The bar shoe is fitted as is the normal shoe and the same heats are used. A little more a! lowance, however, is made for expansion on account of the added frog pressure.

To Open the Toe.-The shoe is heated through- 
out to an even heat and held upright with the bar on the face of the anvil. 'The blows are struck along the toe, thus opening the toe and quarters without changing the bar.

The toe may be opened as in the normal shoe.

To Widen the Heels.-(By lengthening the bar.) (a) When the quarters are too long: Heat the har and the heels to a cherry heat. Hold the shoe in the tongs at the toe and place the inside edge of the hee! on the point of the horn, resting at the point from which it is desired to turn the heel into the bar. Strike on the end of the heel projecting over the horn. Thet: reverse the shoe and proceed in the same manner wit? the other heel.

(b) When the quarters are of the correct length. Heat the bar to a white heat and draw it out by working on the face of the anvil. This will lengthen the bar and at the same time reduce its thickness. After drawing out in this manner, the bar must be lereled with the upper surface unless the frog is so large that it will produce the desired pressure. 'The baı may also be drawn on the point of the horn, working on one-half and then reversing; this method thickens the bar and should be used if the frog is very small. To Close the Hecls.-(By shortening the bar.) (a) When the quarters are of the correct length Heat the bar and heels and, holding one heel on the 
face of the anvil, shoe perpendicular, strike on the elevated heel. This will shorten the bar, also narrowing and straightening the quarters.

(b) When the quarters are too short: Place an inside edge of the triangular part of the bar on the point of the horn and strike on the part projecting over it. This will turn part of the bar into the heel.

(c) When the quarters are too long: Hold th: shoe upright, the center of the bar on the point of the anvil, and strike on the toe. This will push the bar towards the toe and shorten the shoe, bringing the heels closer together.

To Lengthen the Quarters without Changing the Bar.-Draw out the heels on the horn of the anvil as in the normal shoe.

When One Quarter Is Longer Than the Other.To bring the shoe back to its proper shape, heat the shoe throughout and holding it upright with the point of the heel of the longer quarter on the face of the anvil, strike on the upper edge of the shoe directly over the point resting on the anvil.

Thinning the bar is often necessary in the case of a large frog. To accomplish this, the bar is welded at about one-half the required length and then drawn out on the face of the anvil, its lower surface being leveled with the ground surface of the shoe.

In the case of an exceptionally large frog, it is nec- 
essary to curve the bar below the ground surface to allow sufficient room and prevent too much pressure.

To Curie the Bar.--Hold the shoe so that one end of the bar rests on the edge of the face and the other on the horn of the anvil and strike on the center os the upper surface:

Toe- and heel-calks must be used with this shoe ti; insure a level ground surface.

It being difficult for the beginner to estimate the length of shoe required for making the bar, it would be as well to fit the shoe to the outline of the foot before turning in the heels to make the bar.

Resting the Fet'.-Shoeing causes the feet to assume an unnatural condition. No matter how careful or how skilled the shoer, the feet are sure to deteriorate somewhat from their natural state. It is as necessary that the feet be given a rest once a year as it is for the business man to put aside his work and take a vacation of a few weeks in the country or at the seashore.

If possible, turn the horse out to pasture for a month each summer, first having the shoes pulled off and the edges of the wall well rounded to prevent them from breaking too badly. If the feet are in such condition that by allowing the horse to run without shoes he would be foot-sore, have a set of light tips put on. This will prevent the wall at the toes from breaking away 
and at the same time allow the quarters, heels and frog to come into contact with the ground.

The above treatment also allows the feet to regain their natural elasticity and form.

To Repair the Hardie. - When the blade of the hardie is worn down so that it is unrit for further use, take an old rasp and cut off a piece about four inches in length; scarf each end; bend in the center and close it so as to fit over the blacle of the hardie; the scarf should be fitted well down on the shank to hold it in position for taking the weld. In taking the weld, use borax freely, being careful not to overheat the metal. After welding, dress the blade down smooth, and then temper it. You will be well repaid for the time thus taken in repairing the hardies, as it will hold a cutting edge longer than a new hardie.

Narrou and Wide Web Shoes.-It is the writer's opinion that the wide thin shoe is better than the narro: thick shoe. The former keeps the foot closer to the ground and allows the frog to bear weight, and its wide web protects the outer border of the horny sole. the weakest part after the foot has been prepared for the shoe. The concaving of the inner and upper surface of the shoe should be just sufficient to allow for the descending of the horny sole when weight is placed upon the leg and foot, approximately 1-16 of an inch; greater space between the sole and shoe allows dirt and 
gravel to wedge in the opening and causes a bruising of the sensitive structures similar to that found when the shoe has not been properly concaved. With the narrow and thick web shoe, the horny frog is raised further from the ground, thus preventing it from receiving its proper portion of the shock when the foot is planted. Again, the outer border of the horny sole, being unprotected, is liable to a bruise or puncture by coming in contact with sharp stones or other objects.

Rubber Pads and Shoes:-Rubber pads and shoes are modern methods used to prevent slipping on citv pavements or icy roads, and for reducing the concussion when the foot strikes the ground. 'There are many styles of rubber pads on the market and all of them have good qualities as to wear, prevention of concussion and slipping, etc. Some of them are mounted on canvas, while in nther cases leather is used. With many of them it is necessary to pack the feet with hoof-packing, or with tar and oakurn, to prevent dirt from working in between the sole of the foot and the pad. Where dirt can get in, the horse is liable to be lamed by its hardening and acting sinilar to a stone wedged in the sole of the foot. The air cushion pad needs no packing, as with each step the air is freely circulated between the foot and pad, preventing sand from getting under the pad. 'The leather-backed pad is considered superior to the canvas, as the former is 
not as heating to the foot as is the latter, particularly so during summer months.

There are several styles of rubber shoes that are excellent for the same purposes as the rubber pads.

Flaxseed Meal and Tar.-Flaxseed meal is an excellent ingredient to mix with tar for packing the feet. In warm weather tar is thin and watery and does not remain long in the foot; tar with the flaxseed mixell does not dry out so quickly as in case the tar alone is used.

Shoeing of Refractory Horses.--Most horses that can be classed as refractory in shoeing have been brought to this condition by improper handling when green and unaccistomed to the sights and sounds of a shoeing shop.

For shoeing the horse that has been spoiled by poor handling, or one that has a naturally mean disposition, some form of restraint is required; but in each instance no more force should be employed than is absolutely necessary.

I will describe a method of simple design and also very effective in restraining vicions hurses for shoeing:

The Cuff: A strap of double thickness of leather, $\mathrm{I} 8$ inches long and $\mathrm{I} / 2$ inches wide, is sewed to a $\mathrm{D}$ ring 3 inches long and made of $3 / 8$-inch round iron. A piece of thin leather, 9 inches long and 3 inches wide, is sewed on the inside of the strap next to the D- 


\section{Practical and Scientific Horseshoeing}

ring; a buckle and keeper are sewe!l on the outside of the strap.

The Surcingle: 'Iwo 3-inch rings are sewed on the outside of the surcingle, and are so placed that when the surcingle is adjusted, the rings will hang down about midway of the horse's side.

A rope $3 / 4$ inch in diameter and about 20 feet long is also used.

To Raise a Fore Foot: Strap the cuff around the pastern, the ring above the heels. Pass one end of the rope through the ring and tie a half-hitch. The other end of the rope is passed through the ring in the surcingle on the side the foot is to be raised; gently flex the knee, raising the foot and at the same time taking in the slack of the rope. When the loot is in position for shoeing, make the rope fast in the ring; or if a helper is available, let him hold the rope without making it fast. In case the rope is tied to the ring, the knot should be one that can be easily untied in case the horse should throw himself.

To Raise a Hind Foot: Strap the cuff around the pastern, the ring above the heels. Draw the horse's tail to one side and make a loop in it; fasten one end of the rope in the loop by a "single sheet bend." Pass the other end throigh the D-ring and draw it to the rear, where it is made fast to a post or other convenient place.

When it is found that a horse is so vicious that it 
is dangerous to shoe him unless he is rendered helnless, two courses are open. One is to put him in the stocks; the other is to throw him and tie him down. The latter method is a last resort and should be used only when gentler methods have been tried and proven unsatisfactory.

The Fire.-A clear fire without smoke is essential for good work, and the higher degrees of heat can only be obtained from such a fire. In order to procure a suitable fuel for heating purposes, place green coal (slightly dampened) aroind the fire in conical shape; the heat of the fire drives the gases out of the coal, and this coal gradually becomes coke. This coke is next burned, it being replaced by wet coal. In this way a supply of coke is kept up. Green coal is of little use in heating iron or steel, for the reasons that it does not give a high degree of heat, that it sticks to the metal, and that it emits a smoke which interferes with the work.

The depth of the fire should be about 9 inches: the metal is then supported at the place of greatest heat, about 6 inches above the twyer ball. If the metal is too near the twyer ball, the heat is affected by the cold blast. A properly built fire is essential for heating the metal quickly and for the success of the weld.

Clinkers.-Heated steel or iron gives off particles 


\section{Practical and Scientific Horseshocing}

or scales, which remain in the fire. 'These melting particles bind together particles of burned coal, gradually becoming larger and finally forming what is called a clinker. Clinkers give off but little heat and obstruct and spoil the fire; they must therefore be removed as fast as they form. Their presence will be shown by a tendency of the fire to spread and an unusual throwing out of sparks. If indications of clinkers appear. open up the fire with a poker, and as soon as the air touches the clinker it will turn black and become a solid mass, which can be lifted out entire. Trying to drag out the clinker without opening up the fire onl: results in breaking up the clinker and making the fire worse than it was before.

Heats.-There are four degrees of heat that are to be considered by the horseshoer, and they are generally clesignated as the Biack, the Cherry Red, the White, and the Wclding or Sparkling Heat.

The Black Heat, when the shoe is hot but shows no color, is used in making minor changes in shaping. leveling, and in opening nail holes.

The Cherry Red Freat is when the steel or iron shows a bright cherry-colored glow. It is used in the general shaping of the shoe, in pointing the pritchel. and in sharpening the hardy.

The next degree of heat is called the White Heat. because the steel or iron then shows almost that color. This heat is used when it is necessary that the metal 
should be very pliable and easily worked, as in drawing toe-clips, cutting off the heels, in drawing the heels of the shoe, in hot rasping, and in turning heel-calks.

The Welding Heat is sometimes called Sparkling Heat for the reason that the metal then gives off small particles which explode or spark above the fire. As soon as the sparks appear, watch the metal closely and when the part to be welded has a bubbling (fluxing) appearance, it must be withdrawn from the fire and worked immdiately. The success of a wel depends entirely upon the proper heat of the parts at the exact moment the weld is attempted.

A newly made coal fire can be used for ordinary heating, but for a welding heat coke is required. Coke is ordinary coal from which the gases have been driven off by gradual heating. It will be found ready at hand around the edge of the fire. As coke does not smoke. there is no trouble in observing when the metal has reached exact welding heat.

Polo Shoes.-Comnercial rib steel makes a verv desirable material for the shoes for polo ponies. It can be procured in the bar form or in the finished shoe. The rib or rim gives the pony a firm footing, which enables him to make quick starts and halts and to make sharp turns without slipping.

It is desirable to make a light bar for this style of shoe, as the material is very light and the strain on the shoes and nails during severe polo work is liable to spring or spread the heels of the shoe off of the buttress. The bar may be made very thin and light by 
removing the rim. Frog pressure on the bar can be had if desired. By leaving the rim on the bar a very decided grip is obtained for use in stopping the pony suddenly. The shoe may be turned with the rim either on the outside or inside edge of the shoe. Personally, I prefer the shoe with the rim on the outside of the shoe, for by this method the weight is more evenly distributed on the wall of the foot, and the footing is made more secure by having a large ground surface to the shoe. With the rim on the inside edge the greatest weight falls over the white line and outer border of the sole; the ground surface of the shoe is small in circumference and induces a lateral rocking of the foot as well as a too rapid breaking over of the foot at the toe; the pony is liable to be thrown off his gait and caused to stumble or even fall.

A swedge for this style of shoe is easily made by the horseshoer. Take a piece of steel two inches wide, two inches in thickness and five inches in length: forge a shank on one end to fit the hardie hole in the anvil; upset the other end until it will dress to three inches square; allow the steel to anneal and when cold take a hack-saw and cut the grooves the desired depth and angle on the surface of the swedge; finish with a knife-blade file.

Ice Nails.-Ice nails are useful in cases of emergency or in localities where there is little snow and ice. A horse shod with plain shoes may be roughened very quickly by removing four nails from each shoe and replacing them with the ice nails. The first and last nails on each sirle of the shoe should be removed for this purpose. For ordinary work, the ice nail will wear for several days. 


\section{Bonniwell-Calvin Iron Company}

JOBBERS OF

Farriers' Tools and Supplies

A Complete Assortment

of the Best in this Line

Kansas City, - - - - - $\quad$ Missouri

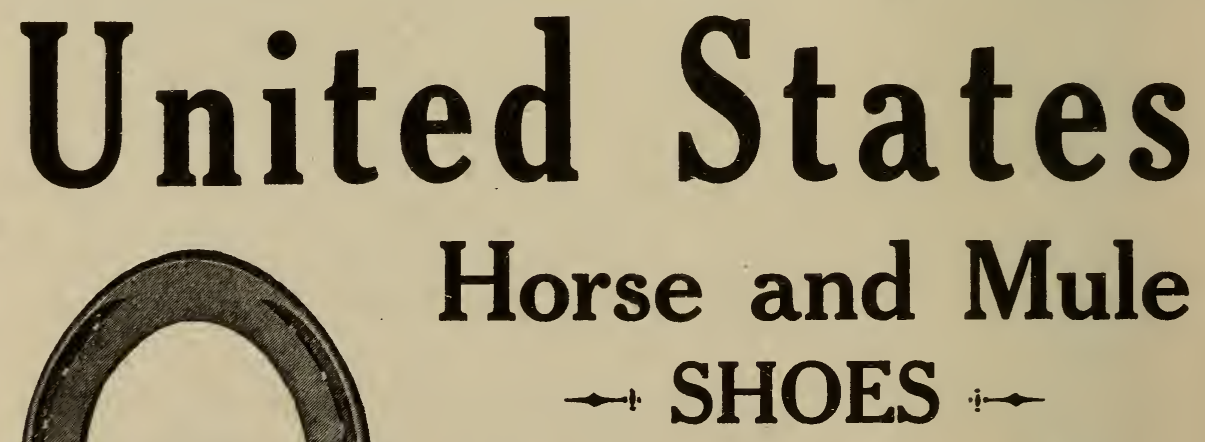

Are Just What You Need Carried in stock by all leading Jobbers Write for New Illustrated C a t a log u e, also Hand some Souvenir Stick Pin, Given Away Free to Al Smiths.

\section{Manufactured by}

United States Horse Shoe Co., Erie, Pa. 


\section{Air-Cushion Rubber ${ }_{\text {SHOE }}^{\text {HORE- PadS. }}$}

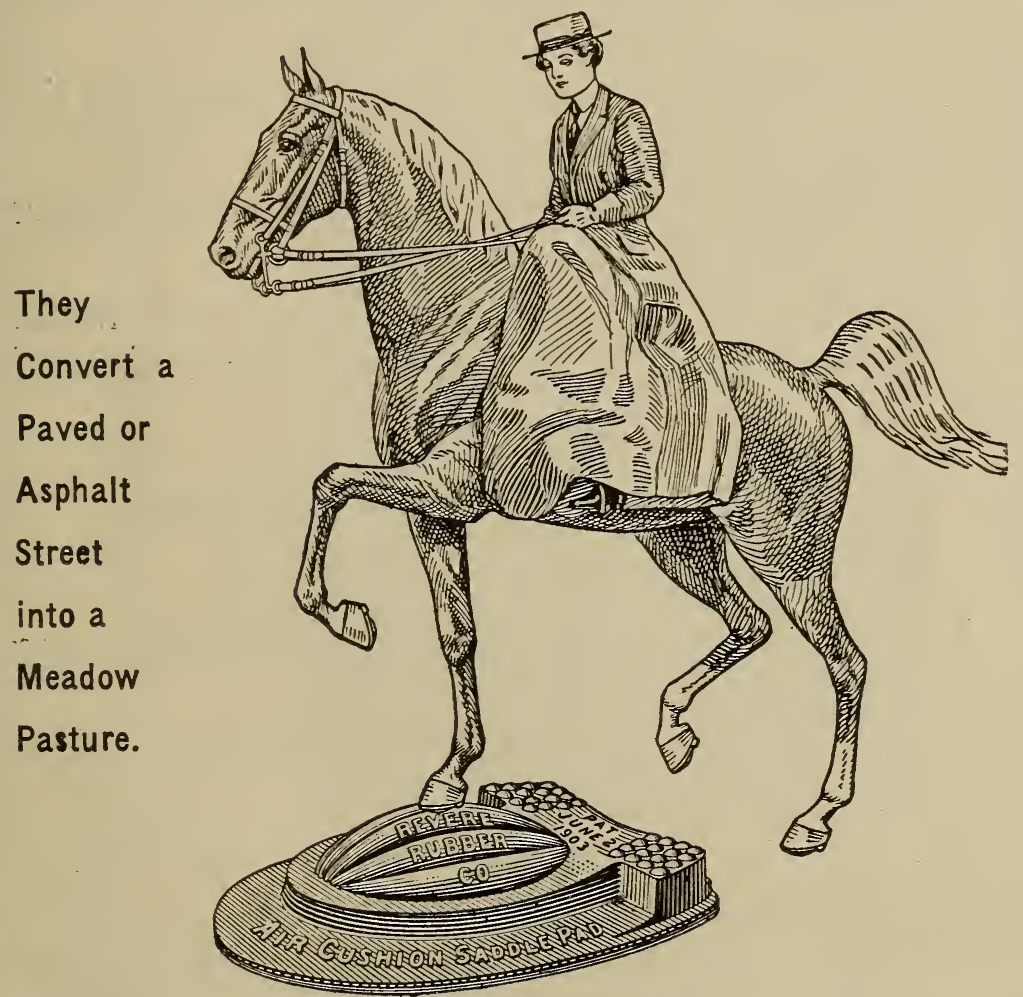

Perfect

Safety

Driving

Over

Any Street

Pavement

with Our

Air-

Cushion

Pads

The

Cushion

Fills with

Air at

Every

Step.

AIR-CUSHION See that Cushion? Air-Cushon
SADDLE PAD. Segular Pad
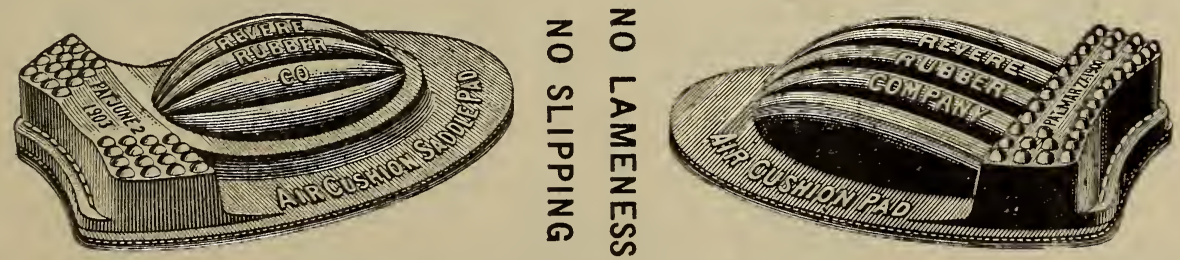

IDEALISM IN HORSE-SHOEING.-They follow closely Nature's sch $3 m e$ in anatomy and physiology, and are therefore correct.
REVERE RUBBER CO.,
BRANCHES: Boston, New York, SOLE MANUFACTURERS, Boston, Mass.
Philadelphia, Pittsburg, Chi- cagn, Kansas City, Minneapo- lis, New Orleans, San Francisco. 


\section{The "Capewell" Horse Nail}

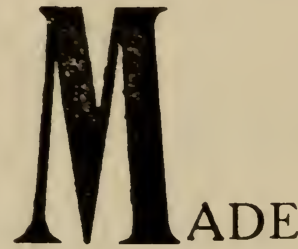

Checked Head Trade-Mark

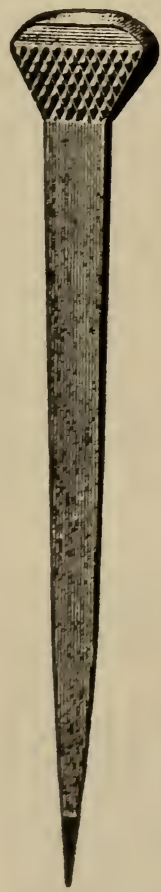
tion.

OF the best materials to be found in the markets of the world.

BY the most modern processes and under the closest inspection

IN all sizes, patterns and styles of head. Each "Capewell" nail has a checked head.

Used by Progressive Shoers Everywhere Because

1 "Capewell" nails drive easiest, thus saving time and trouble.

2 Hold best-the nail that holds the shoe holds the customer.

3 Are safest to use. Do not split or crimp in driving.

4 Every nail in a box of "Capewell" is perfect The shoer gets full value.

No nail represented to be "The Capewell" o the same as "The Capewell" is the same in stock and finish unless it has the check mark on the head as shown in the accompanying illustra-

\section{MADE BY}

The Capewell Horse Nail Company Hartford, Conn., U. S. A.

Largest Makers of Horse Nails in the World. 

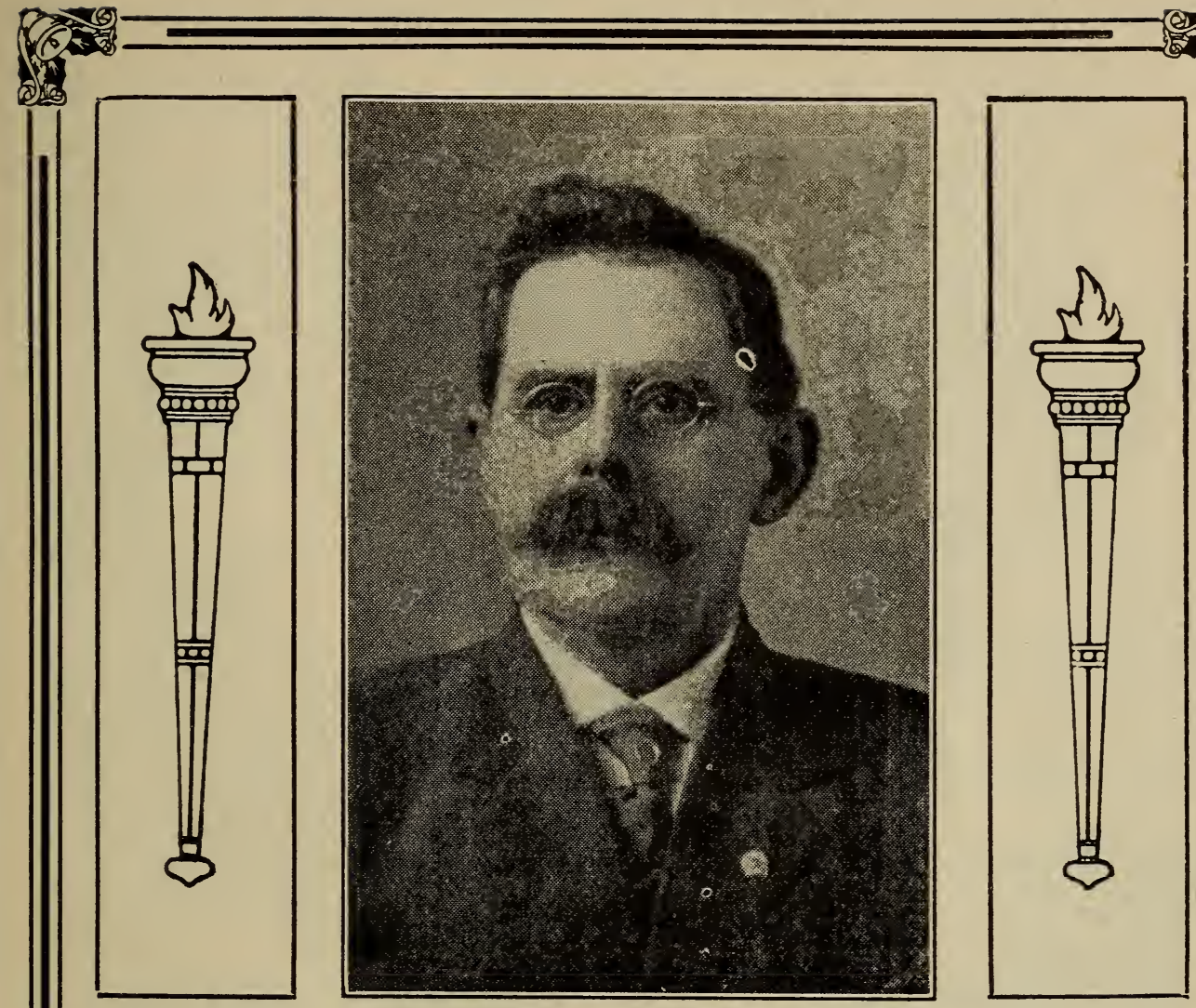

N. LEMOINE, Originator of Lemoine's Hoof Packing
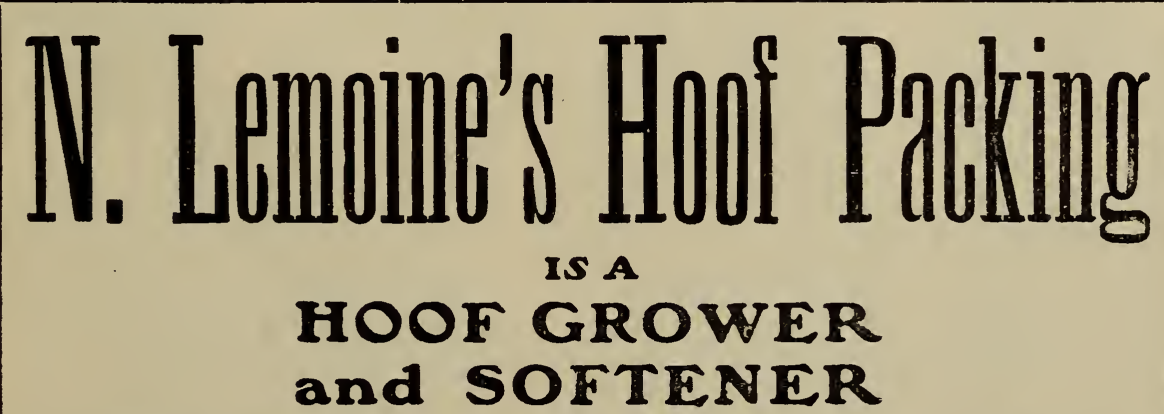

Guaranteed to Cure Thrush and Grow Clean, Healthy Feet

N. Lemoine Co., So. Framingham, Mass. 
CHAMPION SELF-FEED and LEVER-FEED DRILLS.

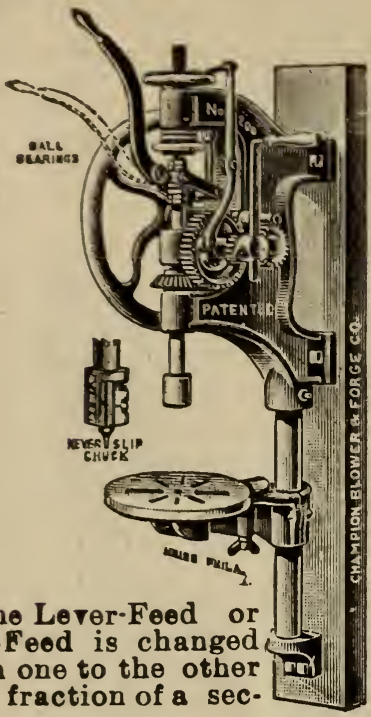

The Lever-Feed or Self-Feed is changed from one to the other ary ond.

$$
\begin{aligned}
& \text { No. } 200 \text { Adjustable } \\
& \text { Lever-Feed }
\end{aligned}
$$

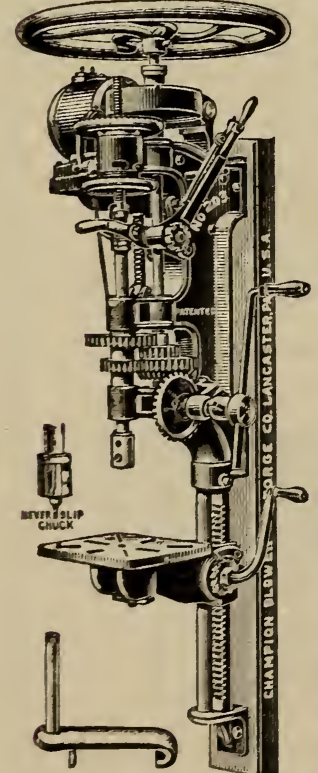

No. 203 Champion Combination Automatic Self-Feed and Double Compound Lever-Feed ELECT RICA L LY DRIVEN Upright Post Drill.

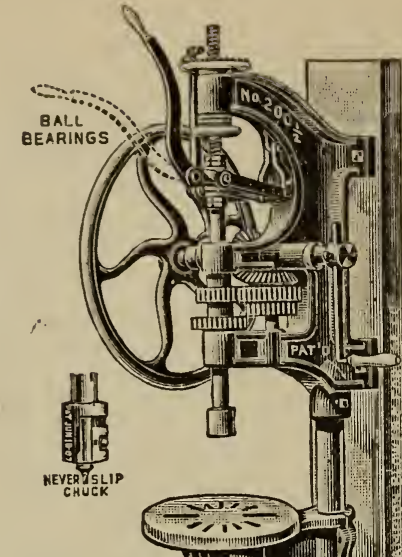

They have

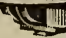

Double Com. HESS gkiLA pound Lever-Feed and Automatir. Self-Feed with instantaneous quick-return of the drill bit with both Feeds.

\section{No. 2001/2 Adjustable Lever-Feed}

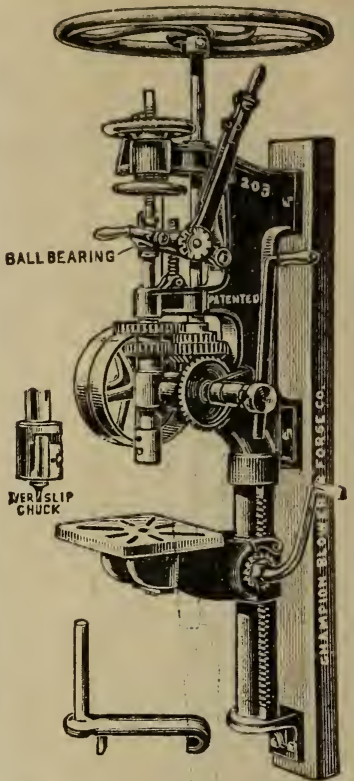

No. 203 Double Com. pound Lever-Feed

REMEMBER There is no TURNING BACK of the FEED Screw NUT WITH EITHER FEED. Write your dealer for prices.
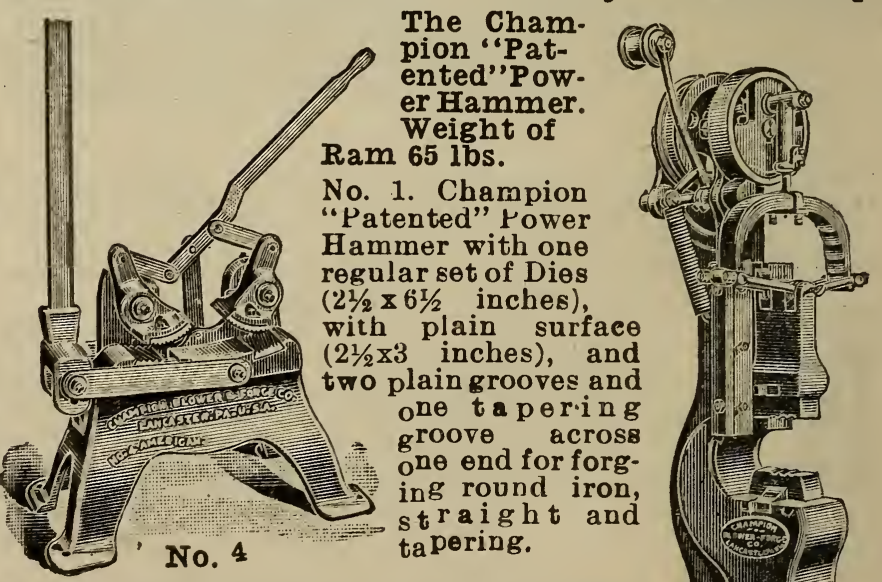

No. 4. American Tire and Axle Shrinker will shrink up to $4 \times 1$-inch roundedge tire, and axles up to $1 \frac{1 / 4}{4}$-inch. Ask for our latest Catalog, showing the largest and most up.to-date line of Blacksmith Touls manufactured under one control in the world. It will pay you to see it.

\section{CHAMPION BLOWER \& FORGE CO.,}

IANCASTER, PA., U. S. A. 

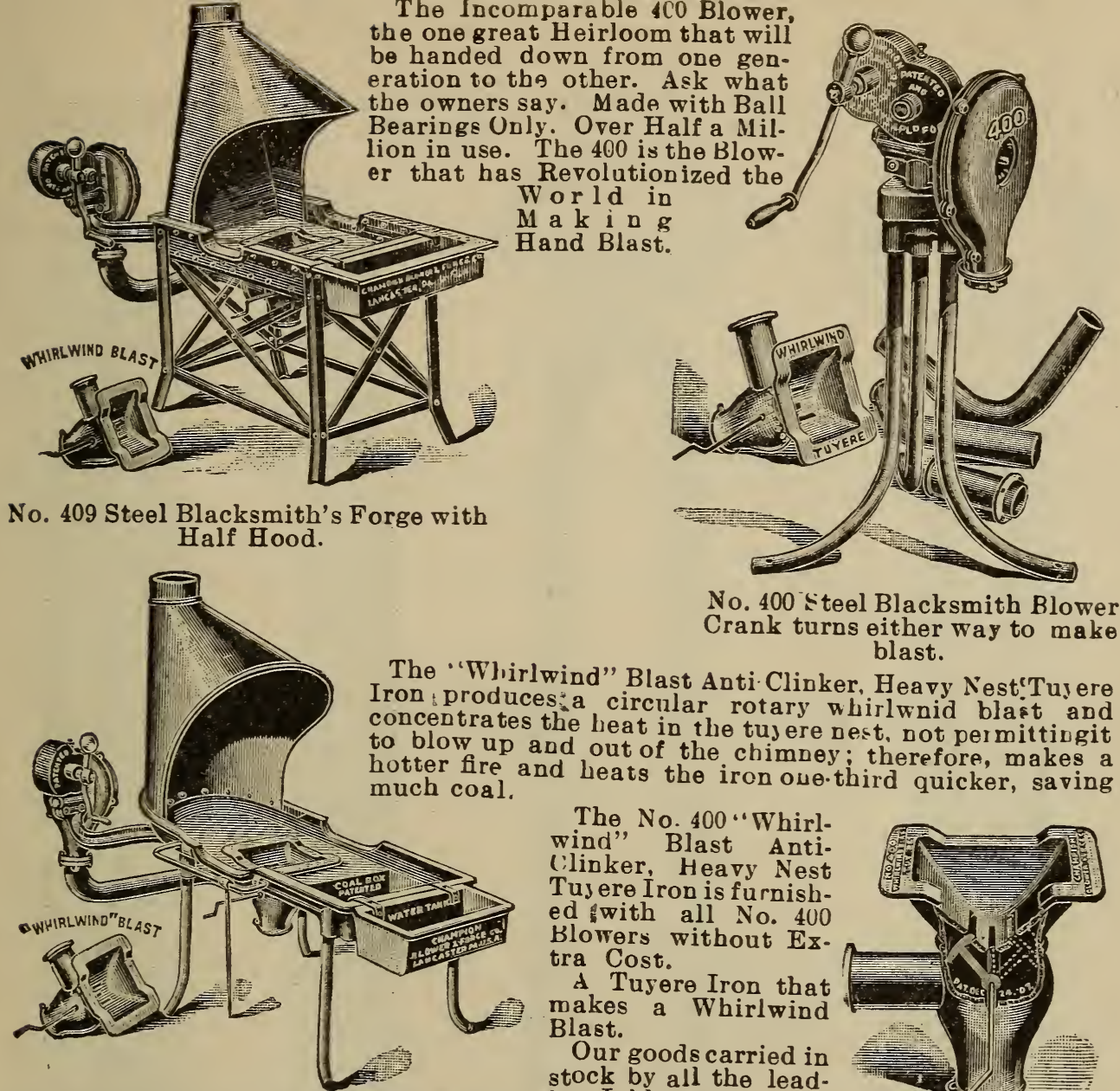

No, 433 Cast Iron Blacksmiths' Forge, Half Hood and sloop Bottom Coal Box.

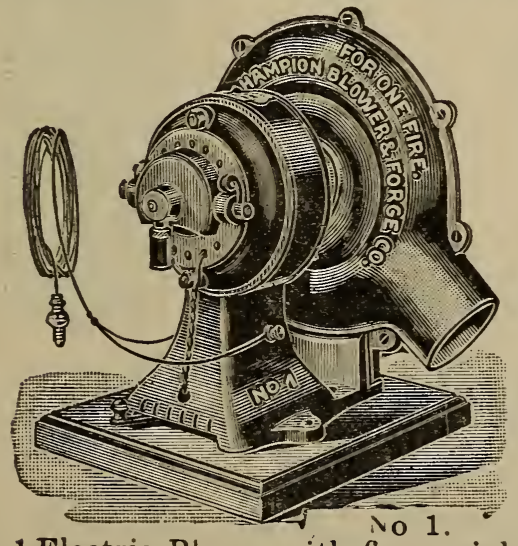

No. 1 Electric Blower with five variable speeds for light and medium work.
No. 400 steel Blacksmith Blower Crank turns either way to make blast.

The "Whirlwind" Blast Anti. Clinker, Heavy Nest'Tuyere plast and and out of the tujere best, not permittingit 作 much coal.

The No. 400 "Whirlwind" Blast Anti(:linker, Heavy Nest Tusere Iron is furnish. ed with all No. 400 Blowers without Ex. tra Cost.

A Tuyere Iron that makes a Whirlwind

Our goods carried in stock by all the lead. ing Jobbers.

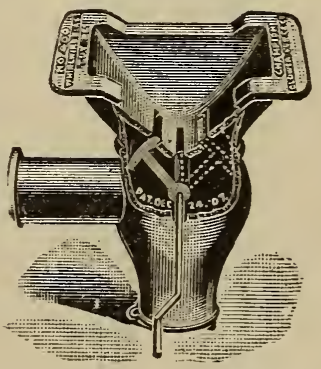

Before purchasing a $\mathrm{Hand}$ Blower, Fnrge, Drill Press, Tire Bender. Tire Shrinker, Screw Plate, Power Blower, or Electric Blower, write for our free catalogue, which always shows the greatest variety of improved Blacksmith Tuols built usder one control in the world.

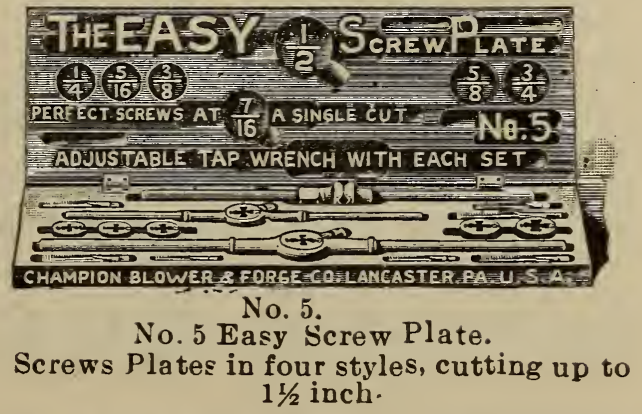


"Heller's Tools Make Better Mechanics."

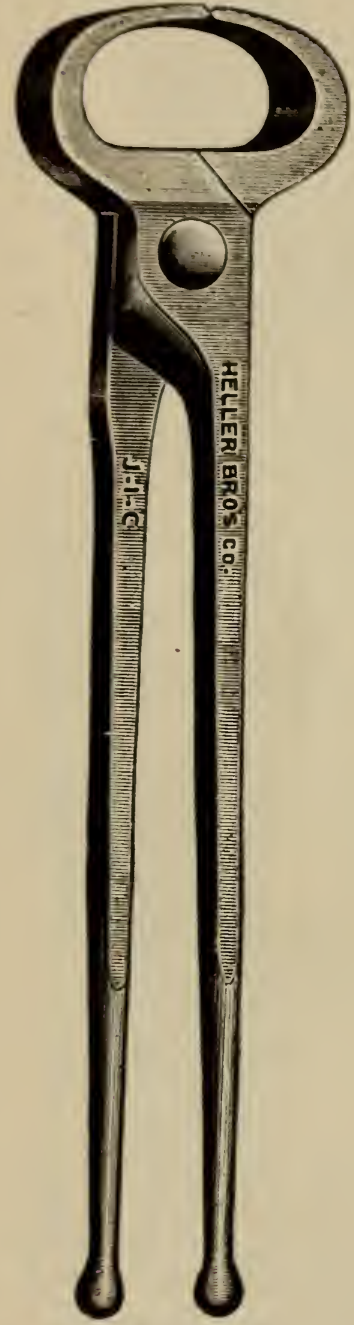

For over half a cent-

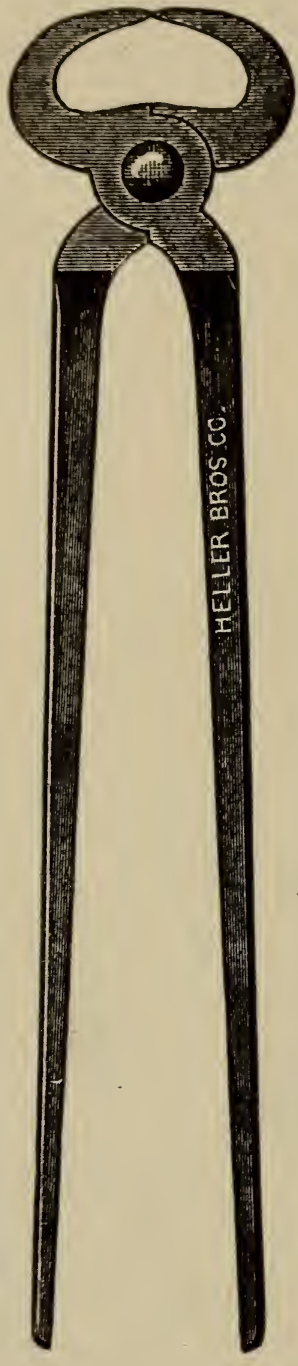

ury, Heller's Rasps, Files and Tools

$\mathrm{h}_{\mathrm{a}}$ ave been The Standard by which all others have

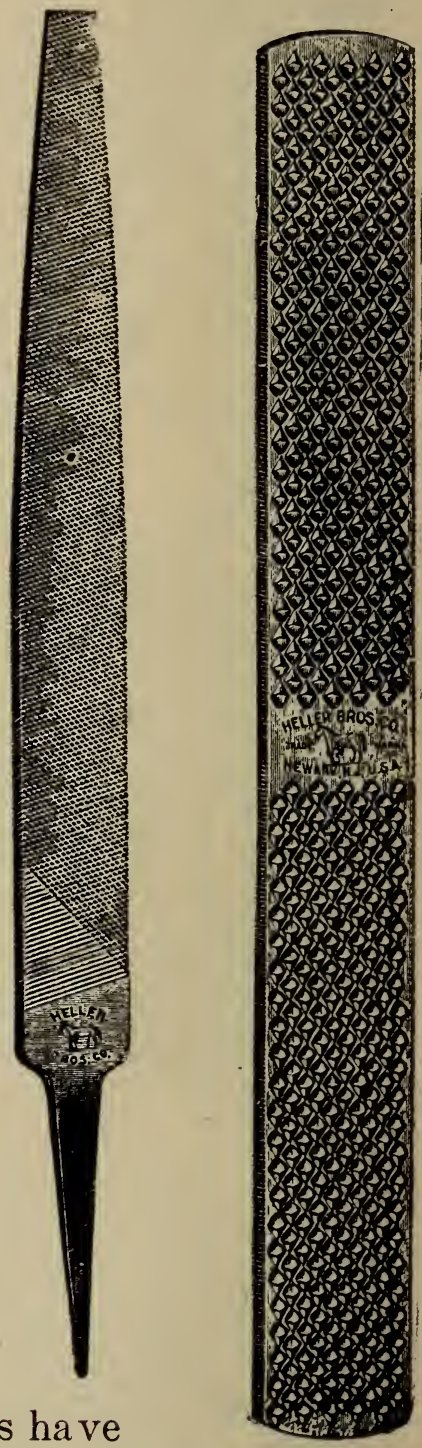

been judged. All made from Refined Clay Crucible Steel.

For sale by the Leading Hardware and Iron Merchants, and made solely by

\section{HELLER BROTHERS CO., \\ NEWARK, N. J.




\section{"PHOENIX"}

\section{Horse and Mule Shoes and Bull Dog Toe Calks}

ARE THE=

Best in Material, Shape and Finish

Most Uniform in Size, Easiest to Fit and Always Give Satisfaction

USED BY THE U. S. ARMY

\section{MANUFACTURED BY}

Phoenix Horse Shoe Company

Largest Horse Shoe Manufacturers in the World

ROLLING MILLS AND FACTORIES:

JOLIET, ILL., POUGHKEEPSIE, N. Y.
OFFICE:

CHICAGO, ILL. 


\section{Champion Tool Company's}

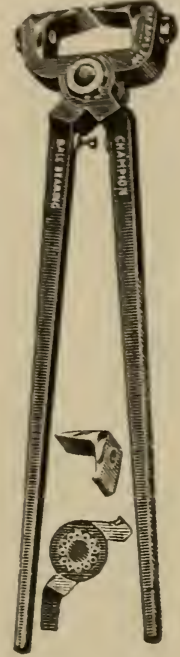

No. 81.

Patented.

\section{Complete \\ Catalog,}

showing

91 labor=

saving

tools, mailed on

No. 87.

Patented.
Farrier's

No. 8I-12-inch and 14-inch; Our Pride Ball-bearing Hoof Shear. Ball-bearing joints. Interchangeable knives. The most popular tool, for the purpose, produced.

No. 87-Clean Claw Driving Hammer; weights 12 to $2 v$ ounces. Claw is always clean. Spring makes that positive,

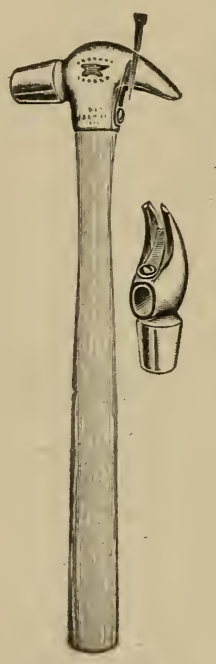

No. 12-Electric Sharpening Hammer; weighs $1 \frac{8}{4}$ to 3 lbs. ('orrugated surface of pein prevents slipping. Every blow counts.

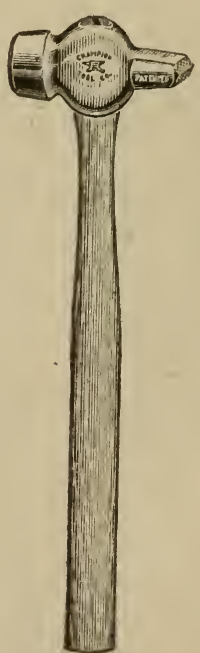

No. 12.

Patented.
No. 80-14-inch and 16-inch; Favorite $\mathrm{Pi}$ cher; one jaw designed square to be used as clinch block.

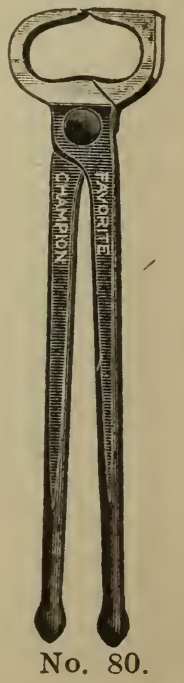

\section{Champion Tool Company \\ Dept. S. MEADVILLE, PA.}


. 
JUN $7 \quad 1912$ 

LIBRARY OF CONGRESS 00028667942 